\title{
Implementation strategies for infection prevention and control promotion for nurses in Sub-Saharan Africa: a systematic review
}

Amy Elizabeth Barrera-Cancedda* (D), Kathryn A. Riman, Julianna E. Shinnick and Alison M. Buttenheim

\begin{abstract}
Background: Despite impressive reductions in infectious disease burden within Sub-Saharan Africa (SSA), half of the top ten causes of poor health or death in SSA are communicable illnesses. With emerging and re-emerging infections affecting the region, the possibility of healthcare-acquired infections (HAls) being transmitted to patients and healthcare workers, especially nurses, is a critical concern. Despite infection prevention and control (IPC) evidence-based practices (EBP) to minimize the transmission of HAls, many healthcare systems in SSA are challenged to implement them. The purpose of this review is to synthesize and critique what is known about implementation strategies to promote IPC for nurses in SSA.
\end{abstract}

Methods: The databases, PubMed, Ovid/Medline, Embase, Cochrane, and CINHAL, were searched for articles with the following criteria: English language, peer-reviewed, published between 1998 and 2018, implemented in SSA, targeted nurses, and promoted IPC EBPs. Further, 6241 search results were produced and screened for eligibility to identify implementation strategies used to promote IPC for nurses in SSA. A total of 61 articles met the inclusion criteria for the final review. The articles were evaluated using the Joanna Briggs Institute's (JBI) quality appraisal tools. Results were reported using PRISMA guidelines.

Results: Most studies were conducted in South Africa $(n=18,30 \%)$, within the last 18 years $(n=41,67 \%)$, and utilized a quasi-experimental design $(n=22,36 \%)$. Few studies $(n=14,23 \%)$ had sample populations comprising nurses only. The majority of studies focused on administrative precautions $(n=36,59 \%)$. The most frequent implementation strategies reported were education $(n=59,97 \%)$, quality management $(n=39,64 \%)$, planning $(n=$ $33,54 \%)$, and restructure $(n=32,53 \%)$. Penetration and feasibility were the most common outcomes measured for both EBPs and implementation strategies used to implement the EBPs. The most common MAStARI and MMAT scores were $5(n=19,31 \%)$ and $50 \%(n=3,4.9 \%)$ respectively.

Conclusions: As infectious diseases, especially emerging and re-emerging infectious diseases, continue to challenge healthcare systems in SSA, nurses, the keystones to IPC practice, need to have a better understanding of which, in what combination, and in what context implementation strategies should be best utilized to ensure their safety and that of their patients. Based on the results of this review, it is clear that implementation of IPC EBPs in SSA requires additional research from an implementation science-specific perspective to promote IPC protocols for nurses in SSA.

Keywords: Infection prevention and control, Global Health, Nursing, Implementation strategies, Implementation outcomes, Sub-Saharan Africa

\footnotetext{
* Correspondence: amyeb@upenn.edu

School of Nursing, University of Pennsylvania, Philadelphia, PA 19104, USA
}

(c) The Author(s). 2019 Open Access This article is distributed under the terms of the Creative Commons Attribution 4.0 International License (http://creativecommons.org/licenses/by/4.0/), which permits unrestricted use, distribution, and reproduction in any medium, provided you give appropriate credit to the original author(s) and the source, provide a link to the Creative Commons license, and indicate if changes were made. The Creative Commons Public Domain Dedication waiver (http://creativecommons.org/publicdomain/zero/1.0/) applies to the data made available in this article, unless otherwise stated. 


\section{Background}

Infectious diseases generate significant morbidity and mortality worldwide [1, 2]. Despite reductions in global prevalence over the last 20 years, a disproportionate amount of the disease burden related to infectious diseases remains in Sub-Saharan Africa (SSA) [3, 4]. Despite impressive reductions in infectious disease burden within SSA [3, 4], communicable illnesses (along with maternal, neonatal, and nutritional causes) comprised $61 \%$ of the disability-adjusted life year (DALY) burden in the region as of 2015 [5]. Half of the top ten causes of poor health or death in SSA are infectious diseases [2, 3]. With rapid economic, social, and geographical shifts occurring in the region [6-8], emerging and re-emerging infectious diseases are playing an increasingly important role in the burden of disease. Recent outbreaks like the Ebola viral disease (EVD) epidemics of 2014 and 2018 have highlighted the impact of infectious diseases on healthcare systems and the communities they serve. In the context of already resource-challenged health care systems, the EVD epidemic of 2014 devastated the healthcare infrastructure of three Western African countries [9], and impacted four more [10]. By April 2016, 28, 616 confirmed EVD cases and 11,310 deaths were reported for the region [9]; the economic cost of the epidemic was estimated at $\$ 3.6$ billion, with $\$ 2.2$ billion in gross domestic product lost in Guinea, Liberia, and Sierra Leone in 2015 [9]. Similar expenditures can be observed for HIV services and care within the region: fiscal requirements for HIV therapy up to 2050 are projected to be as high as $21 \%$ and $80 \%$ of the GDPs of South Africa and Malawi respectively [11]. Currently, an EVD epidemic in the Democratic Republic of the Congo (DRC) is evolving into a significant public health endeavor, leading to the second largest EVD epidemic in history, with over 500 confirmed cases [12]. Infectious diseases and the damage they can cause to patients, healthcare workers, and health systems remain among the most pressing priorities to be addressed in SSA.

Within the broader category of infectious diseases, healthcare-acquired infections (HAIs) are a major challenge. HAI rates are generally higher in low-income compared to high-income countries [13], with substantial variation across and within countries of all income levels: the cumulative incidence of HAIs ranges from 5.7 to $48.5 \%$ within African countries [14]. Traditionally defined, HAIs are infections patients acquire while receiving care in a healthcare facility $[15,16]$. Yet, HAIs that impact healthcare workers providing patient care are equally important, especially nurses [17, 18]. While many different types of health care workers (i.e., laboratory technicians, physicians, water and sanitation staff) are at increased risk of acquiring infectious diseases in the healthcare setting, this study focused on nurses for the following reasons: (a) nurses have unique needs (they spend the most amount of time with patients than any other health worker [19] and operate in highly unstandardized and variable circumstances); (b) nurses are by far the largest cadre of healthcare workers in SSA (even though their needs often take second place or are lumped to those of physicians or other healthcare workers).

Two diseases, EVD and tuberculosis (TB), provide excellent exemplars of infectious diseases that disproportionately affect nurses while caring for patients. A total of 718 healthcare worker EVD infections occurred in West Africa, with 396 (55\%) confirmed cases among nurses [20]. A combined cumulative incidence rate of EVD among nurses was 43.7 per 1000 in the region, compared to 29.5 and 40.4 per 1000 among physicians and laboratory technicians respectively [20]. Similarly, high rates of $\mathrm{TB}$ infections are observed in healthcare workers [21]. The median incidence rate of TB among healthcare workers in SSA was 3871 per 100,000 [21], making the risk of contracting TB among healthcare workers, including nurses, in SSA greater than the risk in the general population in SSA [22]. In terms of HAIs, nurses are often unduly infected, leaving significant burdens on the health system.

Inadequate adherence to infection prevention and control (IPC) standards place millions of patients and healthcare workers, especially nurses, at risk of infectious diseases worldwide, including HAIs. "IPC is a scientific approach and practical solutions to prevent harm caused by infections to patients and health workers" [23]. Effective IPC knowledge and practice are the keystones of a strong healthcare system. The causes of high HAI rates include poor environmental hygiene, inappropriate medical waste disposal, inadequate infrastructure, insufficient equipment, and poor knowledge of infection control protocols all contribute to high HAIs [13].

For example, nurses in SSA may not have enough resources, like biohazard bins or waste bags, to adequately dispose of infectious medical materials [18]. Additionally, nurses may not have access to the following: an adequate healthcare infrastructure to provide safe patient care, familiarity with IPC policies or regulations within their healthcare facilities, and knowledge of effective screening and triage practices to minimize transmission of infectious diseases entering the health facility [18]. The causes of poor IPC places nurses at increased risk of acquiring an infectious disease while serving patients; however, HAIs among healthcare workers and patients are preventable.

The World Health Organization (WHO) [24] has identified a set of evidence-based recommendations on the key components of an IPC program for a national and facility level. These IPC core components include dedicated programs with teams of specialty trained IPC 
professionals, guidelines, training and education, surveillance, implementation of multi-modal IPC strategies, monitoring/auditing and providing feedback, establishing requirements for workload, staffing, and bed occupancy, and ensuring that the built environment, equipment, and materials are available for IPC practices [24]. These core components are the foundation for the two different branches of IPC precautions: standard precautions and transmission-based precautions [25]. Standard precautions are the basics of the IPC precautions. Used for all patients, this branch of precautions includes hand hygiene practices, appropriate use of personal protective equipment (PPE), respiratory hygiene, appropriate patient placement, injection safety, disinfection, and medical waste disposal [26]. When implemented correctly by health workers, these precautions keep the health worker protected from infection and keep infections from spreading among patients [26]. In addition to standard precautions, the second branch of IPC precautions are transmission-based precautions [26]. The three transmission-based precautions are contact, droplet, and airborne [26]. Contact precautions are used when patients are colonized with an infectious agent and the risk of further transmission is high [26]. For some infectious agents, specialized precautions called administrative precautions are used to further control the spread of infection. Administrative precautions focus on reducing the risk of exposure to patients infected with specific infectious diseases [27]. Administrative control activities include screening, diagnosing, and treating infectious agents [27]. For example, TB is an infectious disease that requires both administrative precautions and transmission-based precautions [27]. Rapidly screening TB suspects via intensive case finding expedites patient diagnosis, which allows for therapy to be expedited as well. Once TB patients are placed on effective therapy, they are no longer infectious to others [28-30].

With sufficient resources to advance health system strengthening initiatives, prevention of infectious diseases, including HAIs, is achievable. Within the global health context, many initiatives have used strategies to incorporate IPC evidence-based practices (EBPs), like standard, transmission-based, and administrative precautions, into standard healthcare practice. Many EBPs are known for many healthcare challenges [31]. EBPs, like hand hygiene, are effective interventions known to reduce infectious agents among patients and healthcare workers [32-34]. Unfortunately, EBPs, including those for IPC, are not effectively implemented in many low- and middle-income countries (LMICs) in SSA [35]. Within implementation science, a variety of implementation strategies have been used to integrate EBPs into clinical practice in LMICs. Proctor et al. [36] defines implementation strategies as "methods or techniques used to enhance the adoption, implementation, and sustainability of a clinical program or practice". In SSA, many implementation strategies have been used to promote IPC protocols [32, 37-40]. All of these strategies have produced outcomes associated with the original EBP or the strategy utilized. Additionally, implementation outcomes measure the degree in which implementation strategies have been successfully utilized. Implementation outcomes are "the effects of deliberate and purposive action to implement new treatments, practices, and services [41]. In SSA, implementation outcomes have been measured to assess if IPC EBPs have been successfully implemented.

The Conceptual Model of Implementation Research is a framework that outlines the relationships between an EBP, implementation strategies utilized to promote the EBP, and outcomes of the implementation strategies [42]. This framework provides the conceptual underpinnings for the primary research question of this review: how are implementation strategies used to support IPC promotion for nurses in SSA. Using this model, hand hygiene, waste disposal, and correct PPE use are examples of EBPs. Trainings and stakeholder buy-in sessions are examples of implementation strategies, and number of nurses trained and number of trainings conducted are examples of implementation outcomes. Given the burden of infectious diseases in SSA, the promotion of IPC protocols for healthcare workers is critically needed. Yet, limited literature exists on how implementation strategies have been used to advance IPC, for nurses, a commonly overlooked healthcare worker cohort. To address this gap, the purpose of this review is to synthesize and critique what is known about implementation strategies to promote IPC for nurses in SSA.

\section{Methods}

\section{Search strategy}

A systematic approach was used to identify articles from the following databases: PubMed, Ovid/MEDLINE, Embase, Cochrane, and CINHAL. PubMed and Ovid/MEDLINE were selected for their referencing of the biomedical literature. Embase was selected for its focus on international scholarship and a global audience. Cochrane and CINHAL were selected for their reporting on systematic reviews and nursing literature respectively. Two reviewers (AEBC, KAR) independently searched the databases using the search terms for nurses/ nursing; IPC, standard precautions or transmission-based precautions; and Sub-Saharan Africa or individual countries in the region. The complete search syntax for each database are included in Additional file 1. As per the recommendations of Whittemore and Knafl [43], the reference sections of each article were reviewed for additional studies meeting eligibility criteria: a methodology known as citation indexing. 
Figure 1 depicts the Preferred Reporting Items for Systematic Reviews and Meta-Analyses (PRISMA) flow diagram used to report study findings [44]. The protocol for this review was not registered.

\section{Eligibility criteria}

Inclusion and exclusion criteria were developed to identify research that empirically evaluated or tested implementation strategies to promote IPC protocols for nurses in SSA. Studies were eligible for inclusion if written in English, peer-reviewed, published between 1998 and 2018, implemented in SSA, targeted nurses, and promoted IPC EBPs. All study designs (RCT, crosssectional, cohort, qualitative) were eligible. Studies were excluded if they did not meet the aforementioned criteria. For example, non-empirical studies (reviews, commentaries, briefs, editorials, reports, guidelines) and studies that did not specifically evaluate or test an implementation strategy (e.g., prevalence studies, modeling studies) were excluded from this review.

\section{Study selection and data extraction}

Titles and abstracts identified in the initial search were de-duplicated and then screened using inclusion and exclusion criteria for full-text review. Citation-index searching was conducted on articles that met inclusion criteria following full-text review, and eligible articles were similarly screened. The following implementationrelated data elements were extracted from studies included in the review: author, year of publication, purpose, country, study design, IPC EBPs, implementation strategies, and implementation outcomes.

For each article, implementation strategies and outcomes were categorized based on the definitions produced by Powell et al. [45] and Proctor et al. [41] respectively. Further categorization of implementation outcomes based on their association with the EBPs or implementation strategies to promote the EBPs was conducted. For example, hand hygiene is an EBP. An educational training (implementation strategy) may be provided to nurses to promote the uptake of hand hygiene practices. The outcomes of this initiative may be related to the EBP and/or

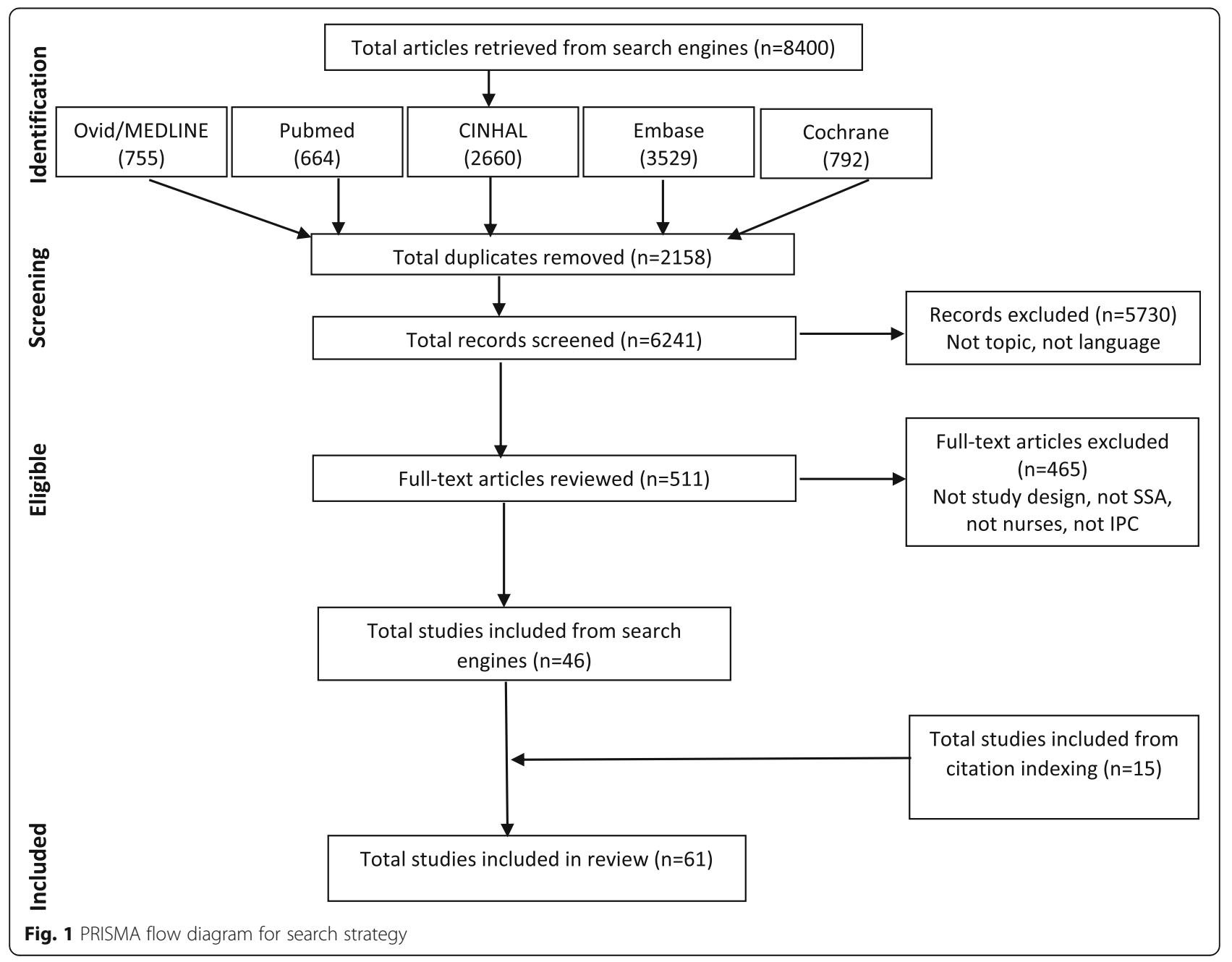


to the training. An example of a possible outcome related to the above scenario for the EBP is penetration (i.e., increased number of nurses practicing hand hygiene out of total number of nurses). An example of a possible outcome associated with the implementation strategy (training) is acceptability (i.e., $95 \%$ of nurses agreed the training material on hand hygiene was good, informative, and useful). Two reviewers (AEBC, KAR) screened all articles for inclusion/ exclusion. After all articles were screened and deemed to meet the inclusion criteria of the review, data extraction was then conducted by the primary reviewer (AEBC).

\section{Quality screening}

Each included article was assessed for quality using tools developed by the Johanna Briggs Institute (JBI). JBI focuses on the promotion of evidence-based practices through effective healthcare measures to a global community [46]. Implementation and translational science are key methodologies embraced and promoted by JBI [46], making these appraisal criteria particularly wellsuited to the purpose and scope of this review.

JBI uses individual assessment tools for each type of study (randomized control trial, cohort, case-study, qualitative investigation, etc.) to assess quality. Study designs that had global cut-off criteria were assessed using that criteria. For studies where no global criteria existed, the reviewers established pre-determined cut-off scores before the appraisal process was initiated. Each JBI tool has specific questions addressing bias, confounding variables, statistical analyses, methodological validity, and outcome reliability [47]. Table 1 contains the quality appraisal and scoring criteria utilized in this review.

For quantitative studies, the JBI-Meta Analysis for Statistics Assessment and Review Instrument (MAStARI) was used. For qualitative studies, the JBI-Qualitative Assessment and Review Instrument (QARI) was used. For mixed methods studies, JBI does not have an appraisal tool. The mixed methods appraisal tool (MMAT) produced by Pluye et al. [49] at McGill University was used. This tool has specific quantitative, qualitative, and integration (mixed methods) questions to assess study quality. Two reviewers (AEBC, KAR) appraised all studies for quality, and an additional reviewer (JES) appraised a random sample of $20 \%(n=20)$ of the articles. Any discrepancy in the appraisal process was discussed by all reviewers and consensus was reached.

\section{Results}

\section{Database and citation indexing search results}

The initial database search produced 8400 results. Further, 2159 duplicates were removed. Of the 6241 studies that remained, 511 met the criteria for fulltext review. Forty-six studies met the inclusion criteria. Citation indexing yielded an additional 15 studies that met the inclusion criteria. A total of 61 studies have been included in this review (see Fig. 1 for PRISMA flow diagram) [32-34, 38-40, 50-104].

Table 2 provides a summary of the individual study characteristics of the studies included in this review. Table 3 provides a table of evidence of the studies in the review. The majority of the studies were conducted in South Africa $(n=18,30 \%)$, within the last 18 years $(n=41$, $67 \%)$, and utilized a quasi-experimental design $(n=22$, 36\%). After South Africa, the other countries where the majority of studies were conducted were Nigeria $(n=5$, $8 \%)$, Kenya $(n=4,7 \%)$, and Zambia $(n=4,7 \%)$. The majority of studies in this review focused on $\operatorname{HIV}(n=24$, $39 \%)$, TB $(n=6,10 \%)$, Ebola $(n=6,10 \%)$, or did not focus on a specific disease or infection $(n=14,23 \%)$. The nondisease studies focused on standard precautions.

\section{Healthcare worker cadres}

This review was conducted to investigate what is known about implementation strategies utilized to promote IPC protocols for nurses. Forty-seven (77\%) studies included healthcare worker samples, including physicians, pharmacists, laboratory technicians, nurse aids, trained birth attendants, residents, and nurses. Fewer studies $(n=14$, $23 \%$ ) had sample populations comprising nurses only.

\section{IPC evidence-based practices}

A variety of EBPs were represented in this review. The majority of studies focused on administrative precautions $(n=36,59 \%)$. Standard precautions and transmissionbased precautions represented forty-one (34\%) and four (7\%) studies respectively. Among the administrative precautions, treatment was the most frequently reported EBP $(n=21,34 \%)$, followed by screening ( $n=$ $11,18 \%)$ and diagnosis $(n=4,7 \%)$. Studies focusing on HIV treatment or TB screening comprised the majority of studies in this section.

Table 1 Quality appraisal summary and criteria

\begin{tabular}{lllll}
\hline Study design & Tool & Response options & Scoring & Cut-off score \\
\hline RCT [47] & MAStARI & Yes, No, Unclear, Not applicable & Yes $=1 ;$ No/Unclear/NA $=0$ & 6 \\
Quasi-experimental [47] & MAStARI & Yes, No, Unclear, Not applicable & Yes $=1$; No/Unclear/NA $=0$ & 5 \\
Cross-sectional [47] & MAStARI & Yes, No, Unclear, Not applicable & Yes $=1$; No/Unclear/NA $=0$ & 5 \\
Qualitative [48] & QARI & Yes, No, Unclear, Not applicable & Yes $=1$; No/Unclear/NA $=0$ & 5 \\
Mixed methods [49] & MMAT & Yes, No, Cannot Tell & Yes =1; No/Cannot Tell =0 & $50 \%$ \\
\hline
\end{tabular}


Table 2 Study characteristics $(N=61)$

\begin{tabular}{|c|c|c|}
\hline Characteristic & $\begin{array}{l}\text { Number of } \\
\text { studies (n) }\end{array}$ & $\begin{array}{l}\text { Percentage of } \\
\text { studies (\%) }\end{array}$ \\
\hline \multicolumn{3}{|l|}{ Sub-Saharan country } \\
\hline South Africa & 18 & 29.5 \\
\hline Nigeria & 5 & 8.2 \\
\hline Kenya & 4 & 6.6 \\
\hline Zambia & 4 & 6.6 \\
\hline Rwanda & 4 & 6.6 \\
\hline Uganda & 4 & 6.6 \\
\hline Ethiopia & 3 & 4.9 \\
\hline Cameroon & 3 & 4.9 \\
\hline Tanzania & 2 & 3.3 \\
\hline Malawi & 2 & 3.3 \\
\hline Sierra Leone & 2 & 3.3 \\
\hline Liberia & 2 & 3.3 \\
\hline Mali & 1 & 1.6 \\
\hline Sudan & 1 & 1.6 \\
\hline Eritrea & 1 & 1.6 \\
\hline Democratic Republic of the Congo & 1 & 1.6 \\
\hline Guinea & 1 & 1.6 \\
\hline Swaziland & 1 & 1.6 \\
\hline Zimbabwe & 1 & 1.6 \\
\hline Botswana & 1 & 1.6 \\
\hline \multicolumn{3}{|l|}{ Publication date } \\
\hline 1998-2003 & 3 & 4.9 \\
\hline 2004-2009 & 17 & 27.9 \\
\hline 2010-2015 & 21 & 34.4 \\
\hline $2015+$ & 20 & 32.8 \\
\hline \multicolumn{3}{|l|}{ Study design } \\
\hline $\mathrm{RCT}$ & 7 & 11.5 \\
\hline Quasi-experimental & 22 & 36.1 \\
\hline Cohort & 13 & 21.3 \\
\hline Cross-sectional & 12 & 19.7 \\
\hline Mixed methods & 3 & 4.9 \\
\hline Qualitative & 3 & 4.9 \\
\hline Multi-modal & 1 & 1.6 \\
\hline \multicolumn{3}{|l|}{ Healthcare Workers } \\
\hline $\begin{array}{l}\text { Healthcare workers (physicians, } \\
\text { nurses, laboratory techs, etc.) }\end{array}$ & 47 & 77.0 \\
\hline Nurses only & 14 & 22.9 \\
\hline \multicolumn{3}{|l|}{ Diseases/infections } \\
\hline HIV & 24 & 39.3 \\
\hline $\mathrm{TB}$ & 6 & 9.8 \\
\hline Ebola & 6 & 9.8 \\
\hline Multiple diseases & 3 & 4.9 \\
\hline Malaria & 2 & 3.3 \\
\hline
\end{tabular}

Table 2 Study characteristics ( $N=61$ ) (Continued)

\begin{tabular}{|c|c|c|}
\hline Characteristic & $\begin{array}{l}\text { Number of } \\
\text { studies }(n)\end{array}$ & $\begin{array}{l}\text { Percentage of } \\
\text { studies (\%) }\end{array}$ \\
\hline CLABSI & 1 & 1.6 \\
\hline VAP & 1 & 1.6 \\
\hline SSI & 1 & 1.6 \\
\hline Bloodborne (non- CLABSI) & 1 & 1.6 \\
\hline STIs (non-HIV) & 1 & 1.6 \\
\hline $\begin{array}{l}\text { None (hand hygiene, disinfection } \\
\text { focused) }\end{array}$ & 14 & 23.0 \\
\hline \multicolumn{3}{|l|}{ Evidence-based practices } \\
\hline Standard Precautions & 21 & 34.4 \\
\hline Multiple SP & 11 & 18.0 \\
\hline Hand hygiene & 8 & 13.1 \\
\hline Disinfection & 1 & 1.6 \\
\hline Waste management & 1 & 1.6 \\
\hline Transmission-based precautions & 4 & 6.6 \\
\hline PPE & 1 & 1.6 \\
\hline Isolation/quarantine & 1 & 1.6 \\
\hline Immunization & 1 & 1.6 \\
\hline Post-exposure prophylaxis & 1 & 1.6 \\
\hline Administrative precautions & 36 & 59.0 \\
\hline Treatment & 21 & 34.4 \\
\hline Screening/surveillance & 11 & 18.0 \\
\hline Diagnosis & 4 & 6.6 \\
\hline \multicolumn{3}{|l|}{ Quality assessment score } \\
\hline MAStARI 4 & 1 & 1.6 \\
\hline MAStARI 5 & 19 & 31.1 \\
\hline MAStARI 6 & 10 & 16.4 \\
\hline MAStARI 7 & 16 & 26.2 \\
\hline MAStARI 8 & 5 & 8.2 \\
\hline MAStARI 9 & 3 & 4.9 \\
\hline MAStARI 10 & 1 & 1.6 \\
\hline MAStARI 11 & 2 & 3.3 \\
\hline QARI 5 & 1 & 1.6 \\
\hline QARI 6 & 0 & 0.0 \\
\hline QARI 7 & 1 & 1.6 \\
\hline QARI 8 & 2 & 3.3 \\
\hline MMAT 0\% & 0 & 0.0 \\
\hline MMAT 50\% & 2 & 3.3 \\
\hline MMAT 75\% & 1 & 1.6 \\
\hline MMAT 100\% & 0 & 0.0 \\
\hline
\end{tabular}

Only four (6\%) studies focused on transmission-based precautions. Each study reported on a unique precaution. Transmission-based studies focused on correct PPE use, appropriate patient placement, immunization, and post-exposure prophylaxis. 


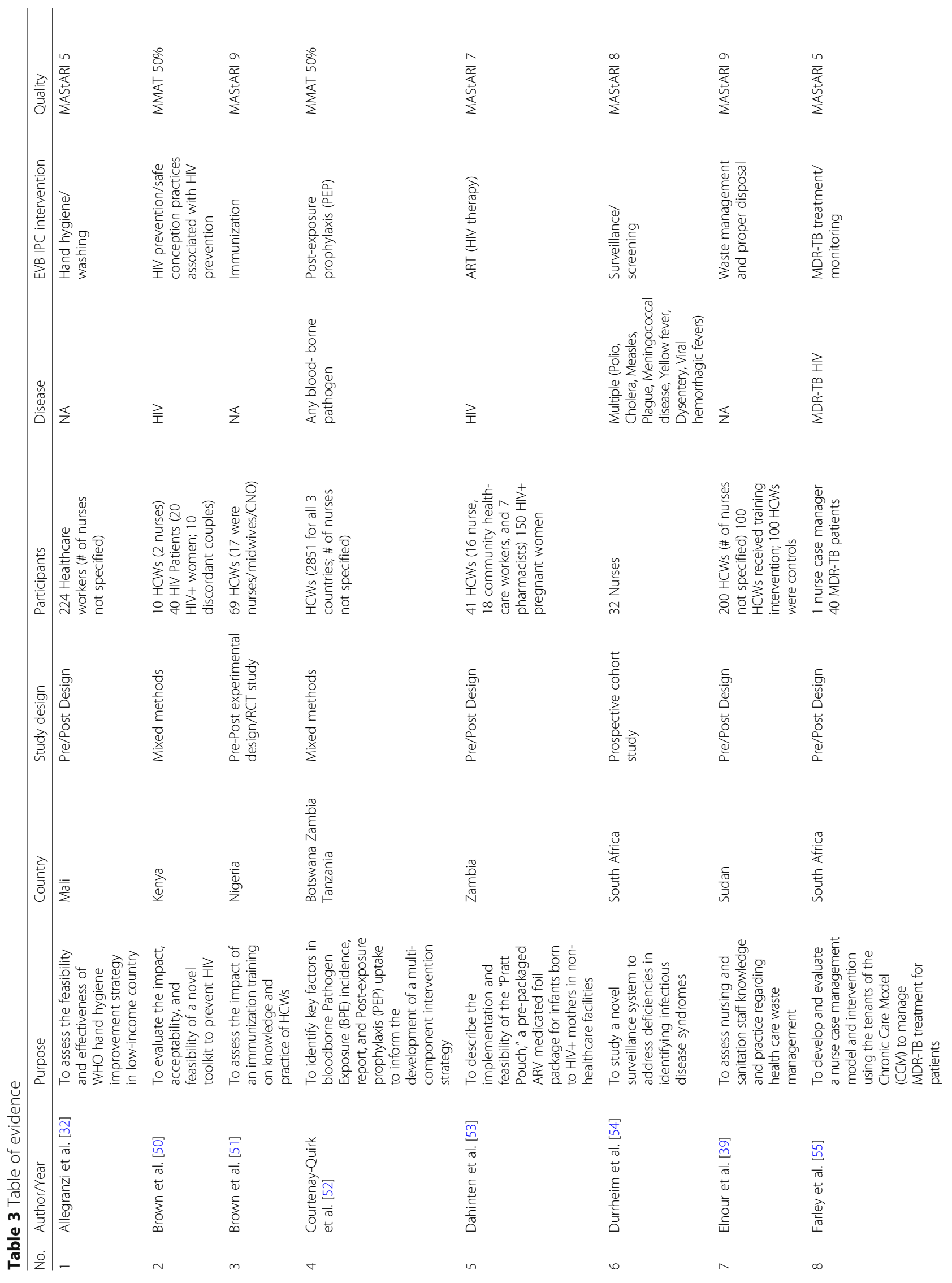




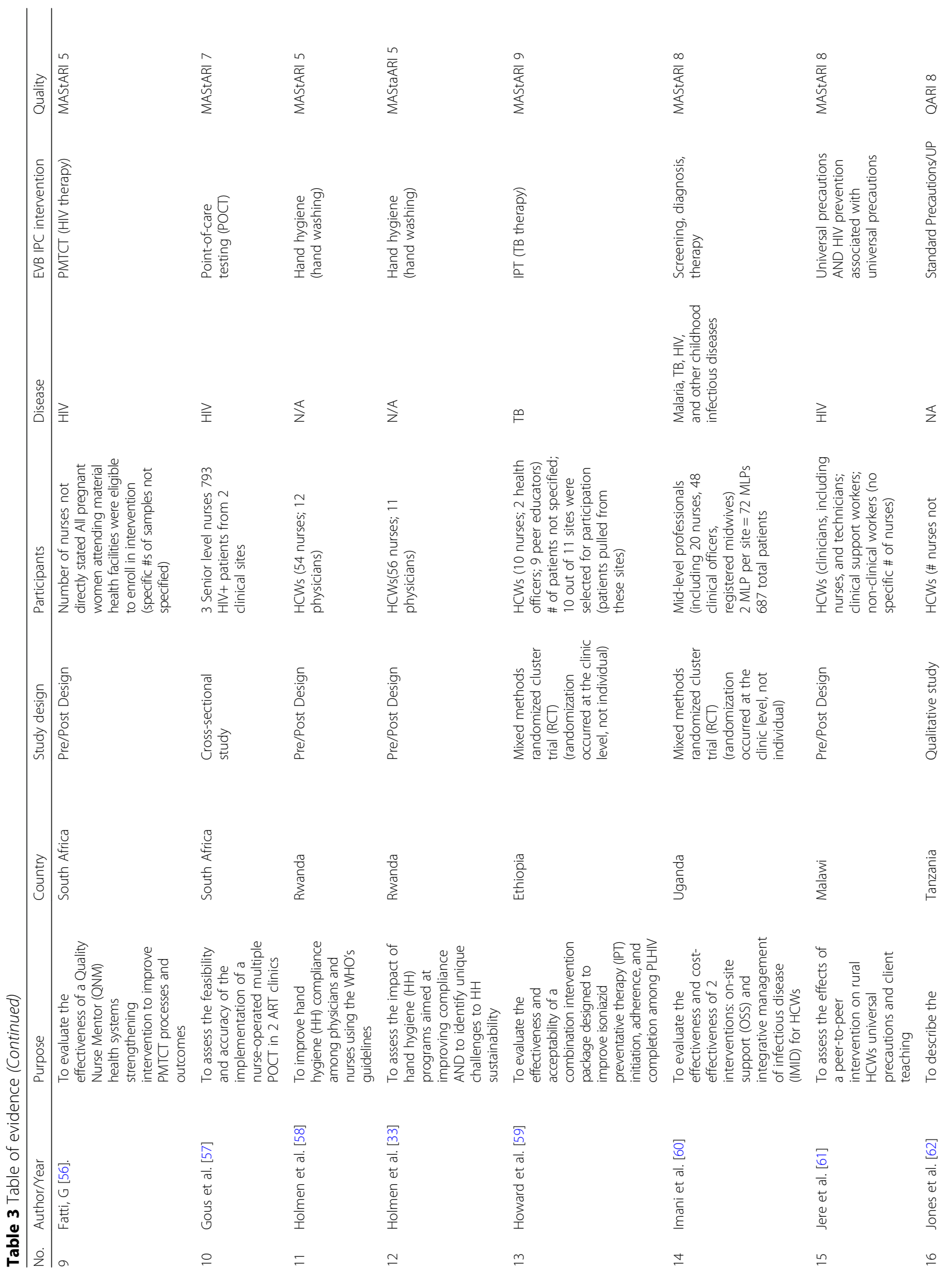




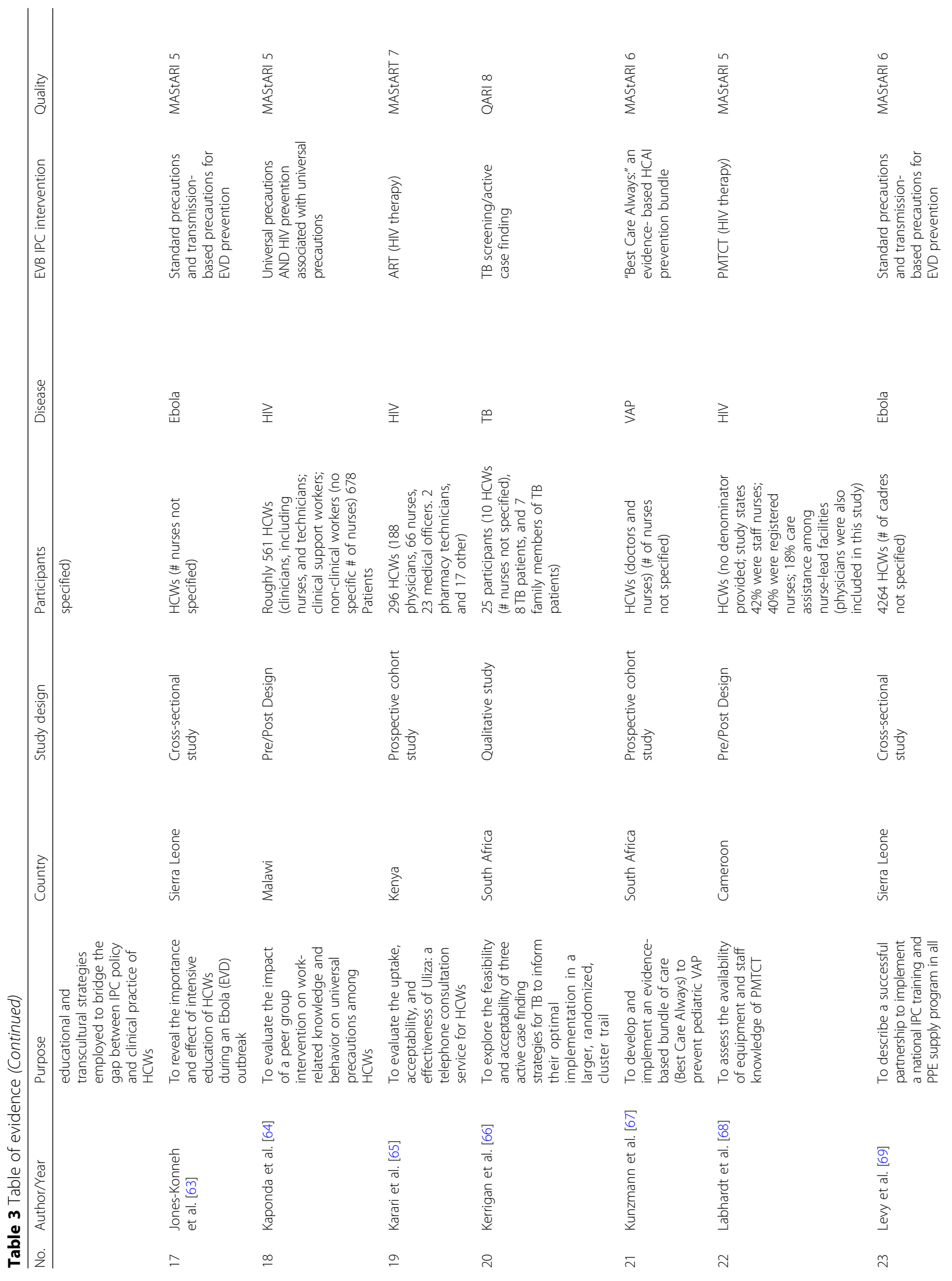




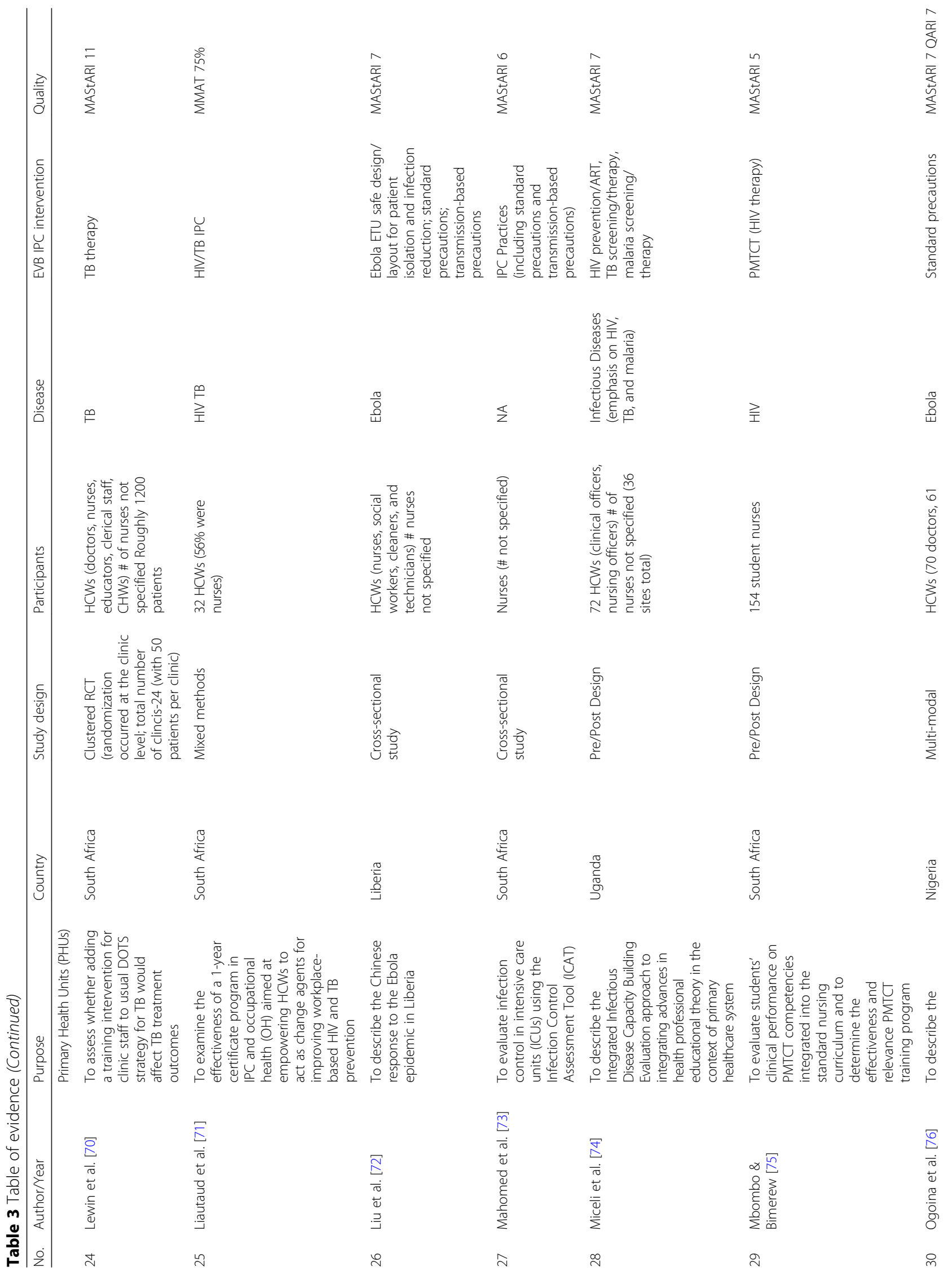




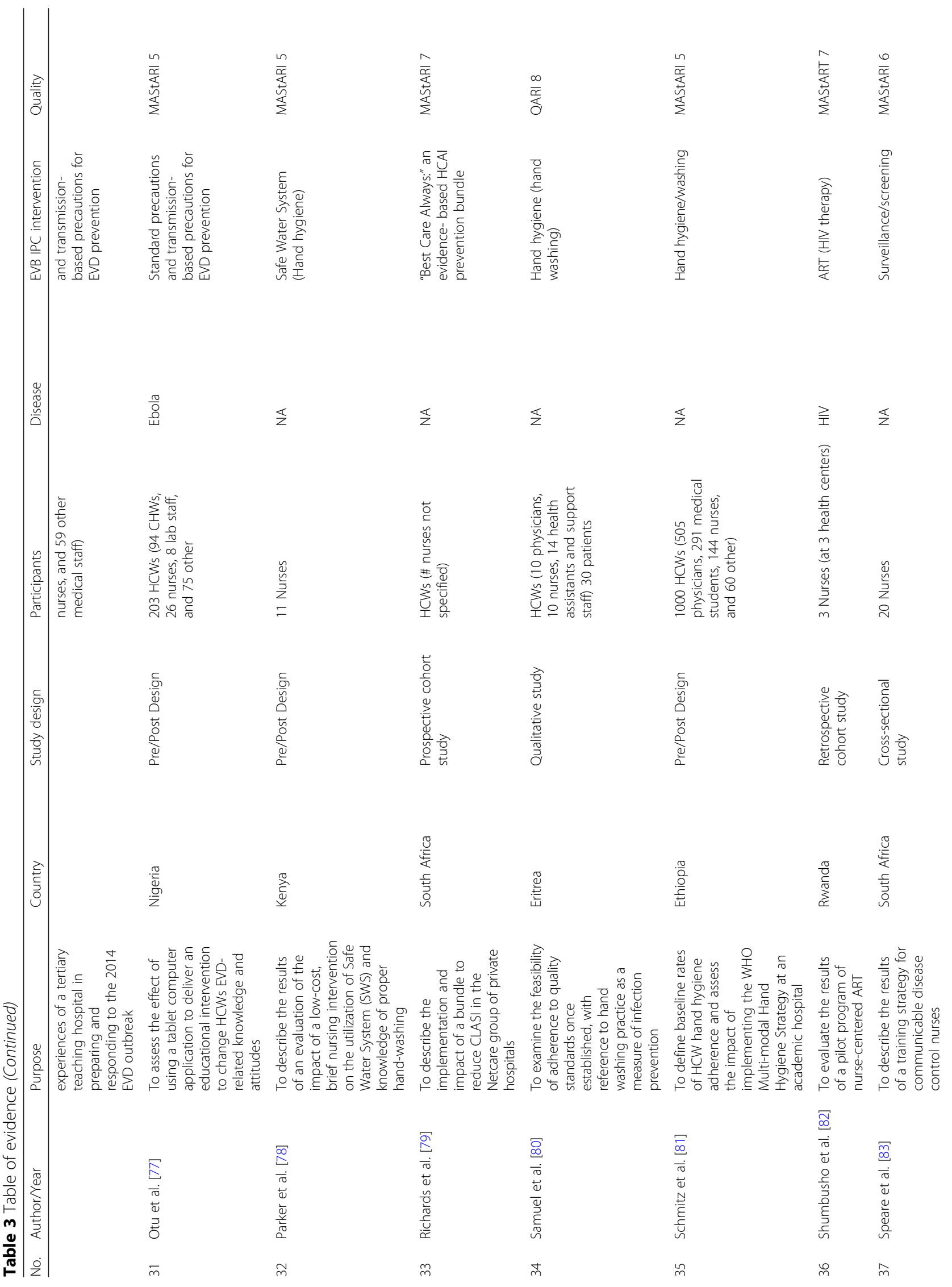




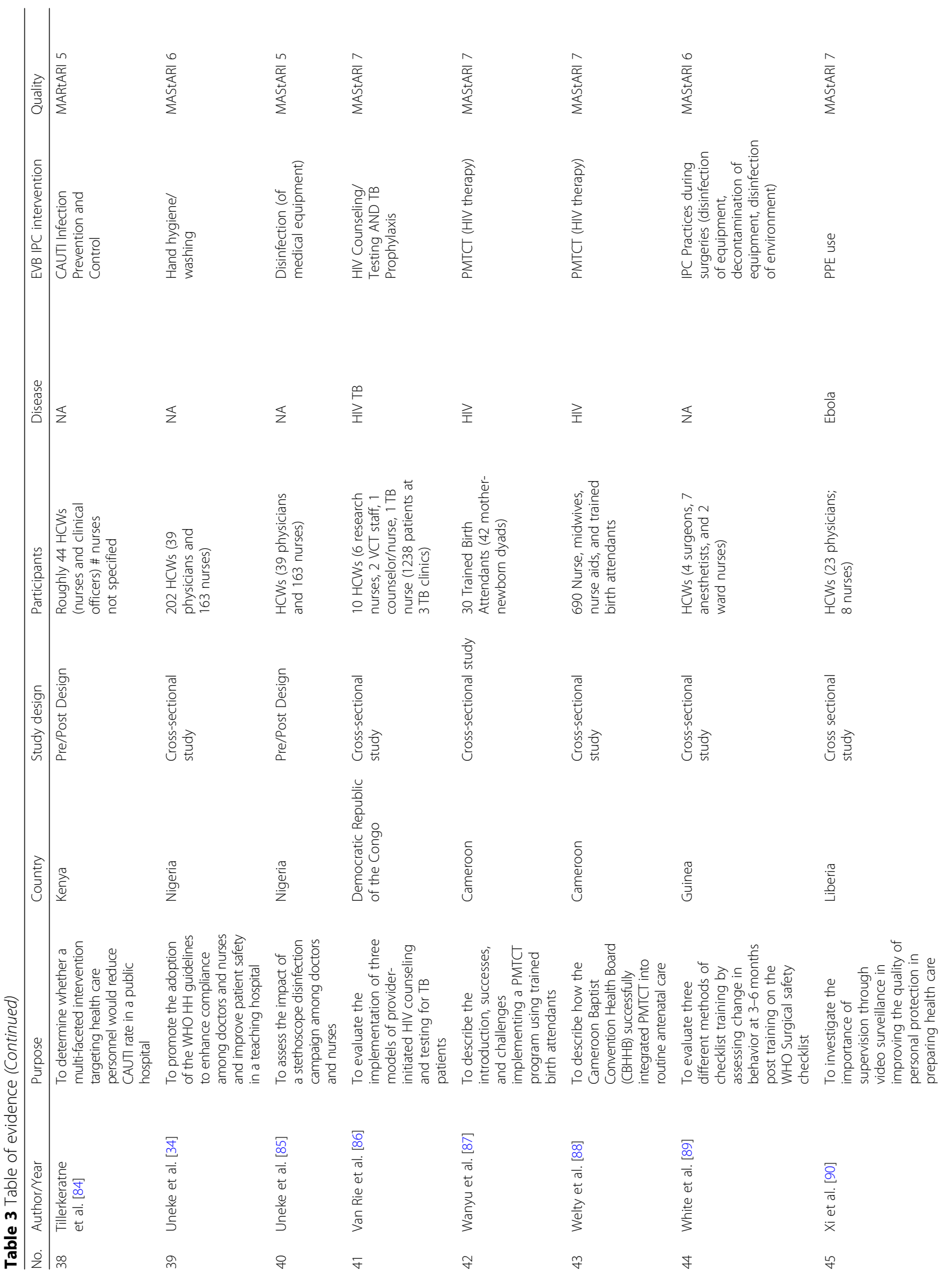




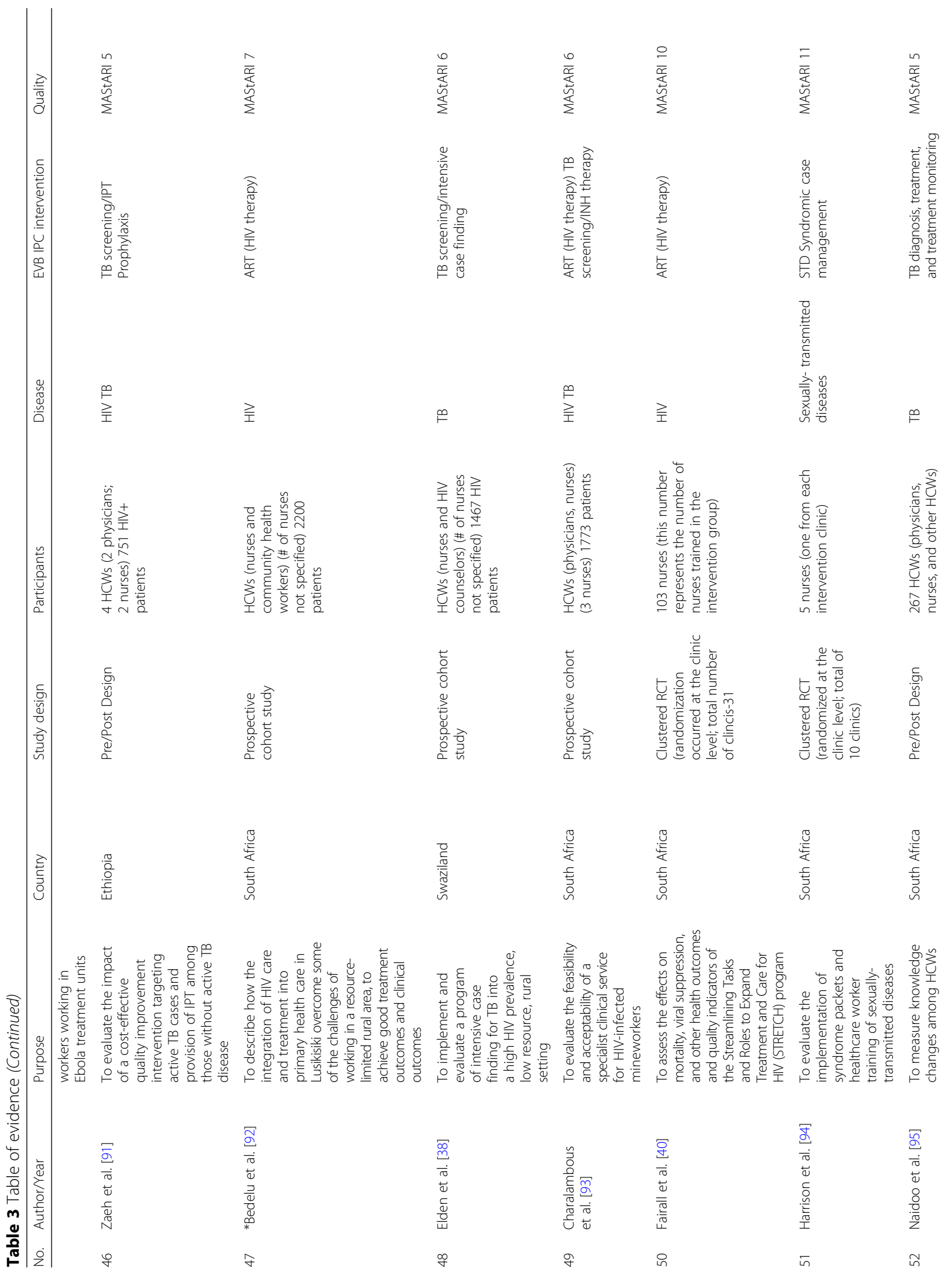




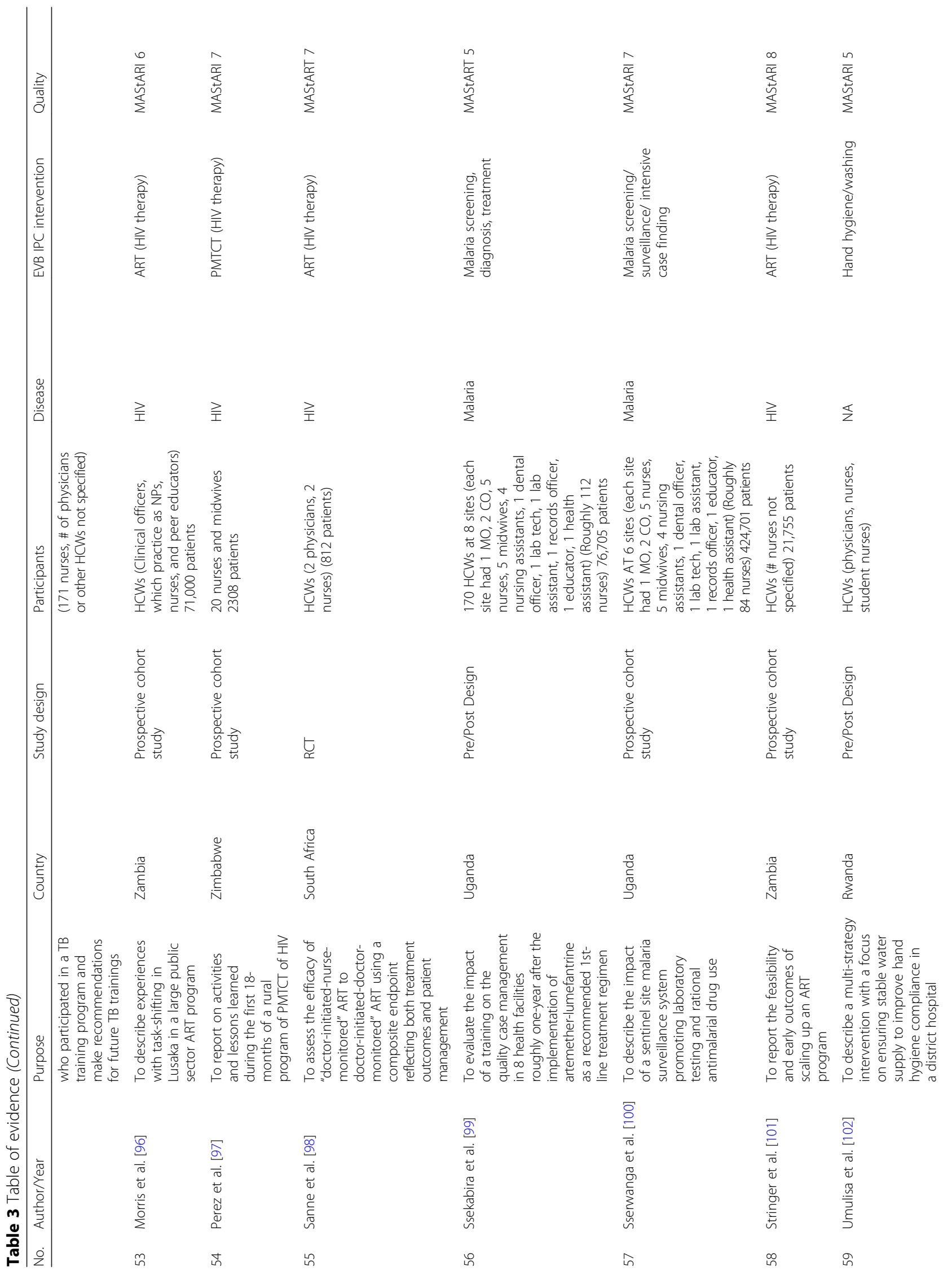




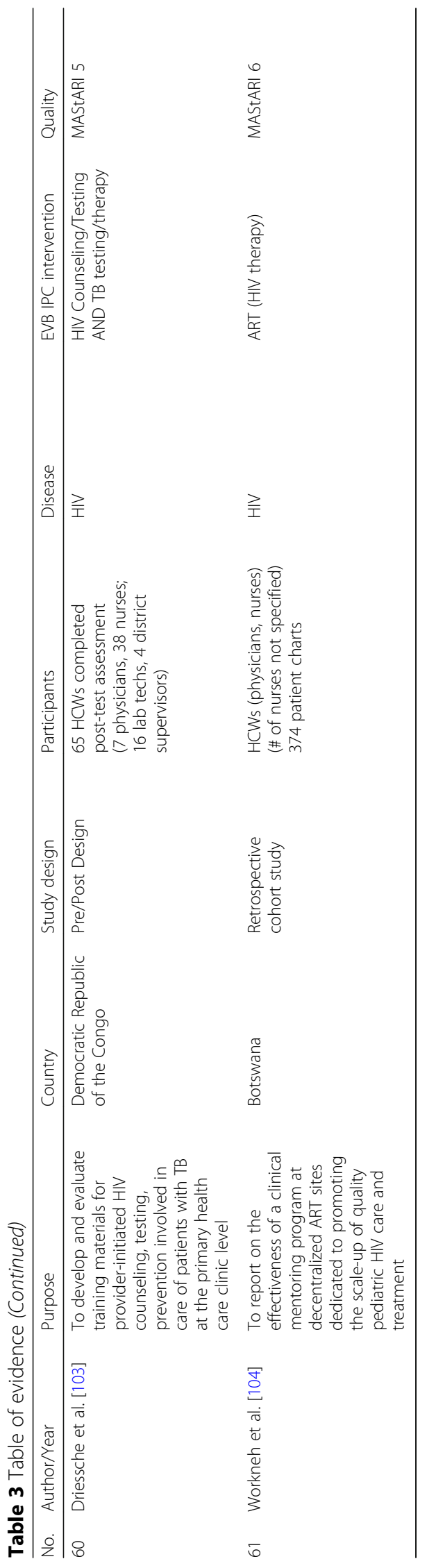


Studies that addressed standard precautions did so by incorporating multiple precautions $(n=11,18 \%)$ or focused on hand hygiene only $(n=8,13 \%)$. Other studies that focused on standard precautions addressed medical equipment disinfection or appropriate waste management.

\section{Implementation strategies}

The most frequent implementation strategies used to promote IPC protocols in included studies were education $(n=59,97 \%)$, quality management $(n=39,64 \%)$, planning $(n=33,54 \%)$, and restructure $(n=32,53 \%)$. A variety of educational strategies were used to promote IPC protocols for nurses. Strategies used included didactic lectures, simulations, on-site mentorship, visual reminders, and demonstrations. Quality management strategies generally consisted of audit and feedback sessions provided to nurses in real time to promote the uptake of an IPC EBP. Planning strategies consisted of collaborations, partnerships, or buy-in sessions that were established at a higher administrative level for nurse IPC involvement. Planning strategies were mostly utilized in conjunction with other strategies. For example, a partnership between the government of a country and an academic institution may be formalized to provide nurses training or mentorship on IPC protocols. Planning strategies were also used to inquire about nurses' experiences with IPC EBPs. A variety of restructure strategies were used to promote IPC. Nurses may be task-shifted to include IPC activities within their scope of work, provided additional resources (i.e., alcohol-based hand gel) to make adhering to IPC protocols easier, or promoted to a higher nursing position whereby IPC became the focus of the new role. Only eight $(n=8,13 \%)$ studies used financing incentives to promote IPC protocols among nurses. When used, a financial strategy was generally associated with external funders providing resources to initiate an EBP intervention or providing over-time compensation to healthcare workers. For example, the Elizabeth Glaser Pediatric AIDS Foundation, the Axios Foundation, and the Boehringer Ingleheim Pharmaceutical Company provided funds to initiate an antiretroviral therapy (ART) initiation program for HIV patients in Cameroon [88]. Zero $(0 \%)$ policy strategies were used.

An exhaustive list of implementation strategies is provided for each study in Table 4. Bolded strategies targeted nurses. In order to be included in this review, studies needed to report the use of implementation strategies for nurses. Many studies used implementation strategies that targeted patients, non-nurse healthcare workers, or aspects of the healthcare system. Few studies used implementation strategies solely for nurses. A summary of implementation strategies used for nurses and non-nurses (i.e., patients or a healthcare system-specific matter) is provided in Table 5. Most studies used education $(n=58,95 \%)$ for nurses; a drastic contrast to the number of studies that used education $(n=1,2 \%)$ for non-nurses. Other discordant results between strategies used for nurses compared to strategies used for non-nurses included planning, restructure, and finance. These strategies were used more for nonnurses than nurses. Twenty-one (34\%), 25 (41\%), and six $(10 \%)$ studies used planning, restructure, and finance strategies respectively for non-nurses. Planning, restructure, and finance were used in $12(20 \%)$, seven (12\%), and two (3\%) studies respectively for nurses.

\section{Implementation outcomes}

For this review, the outcomes of the studies have been analyzed into two parts: outcomes associated with the EBPs and outcomes related to the implementation strategies used to promote an IPC EBP.

\section{Implementation outcomes for EBPs}

All implementation outcomes, except cost, were measured in the studies of this review. Most studies reported penetration $(n=22,37 \%)$ and feasibility $(n=13,21 \%)$ as the most common outcomes produced (see Table 5). Four (7\%) and 18 (30\%) studies measured penetration for nurses and non-nurses respectively (see Table 5). For the non-nurse category, penetration was measured as patient agreement to initiate an EBP (i.e., screening for TB or antiretroviral therapy (ART) uptake). Feasibility was frequently measured as nurse report that EBPs could be implemented within their scope of work. Additionally, feasibility was used to report barriers to EBP implementation. For example, limited hospital infrastructure (i.e., no running water) was identified as a limitation to hand hygiene adherence among nurses.

Few studies measured adoption $(n=5,8 \%)$ and sustainability $(n=5,8 \%)$. Adoption was discussed as patient willingness to accept an EBP with nurse support, facilitylevel uptake of an EBP, or nurse report of healthcare improvements as a result of an implemented EBP. Sustainability was measured as nurses' ability to maintain an EBP for a few weeks or longer. Four (7\%) studies discussed acceptability. Fidelity was also discussed in three (5\%) studies. Fidelity was reported as adherence to an EBP by nurses. One (2\%) study addressed appropriateness, and zero (0\%) studies reported cost. Lastly, 21 (35\%) studies did not measure any EBP outcome. In these studies, the outcomes of interest were related to the implementation strategies. Table 4 provides a complete list of implementation outcomes associated with EBPs for each study. Nurse-specific outcomes associated with EBPs are bolded in Table 4. 

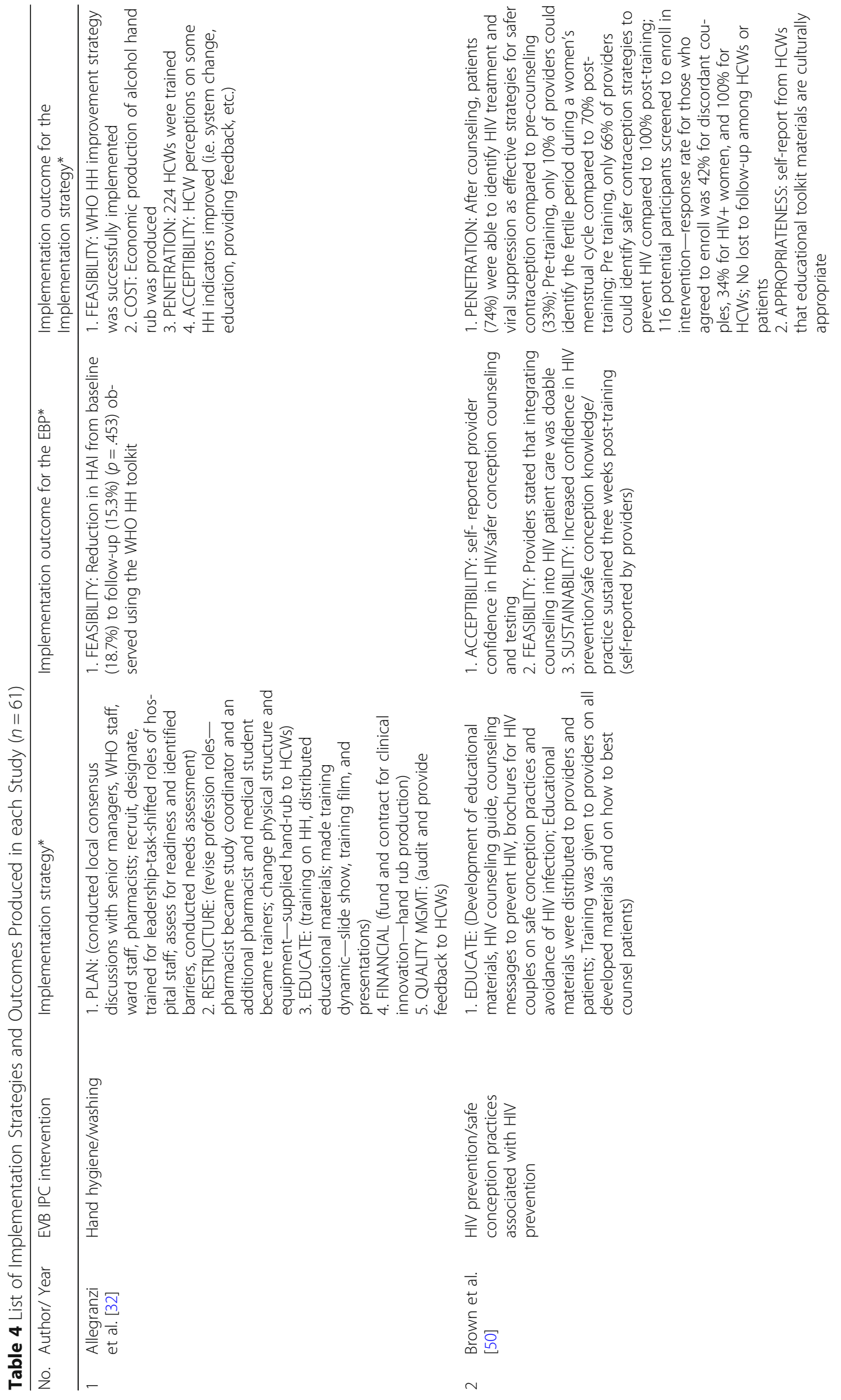

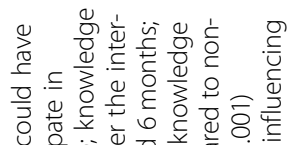

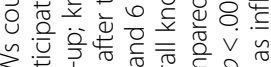

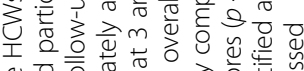

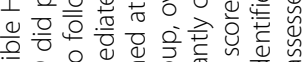

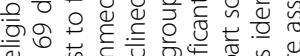

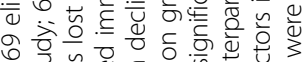

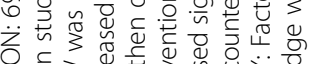

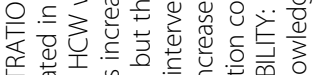

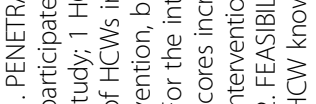

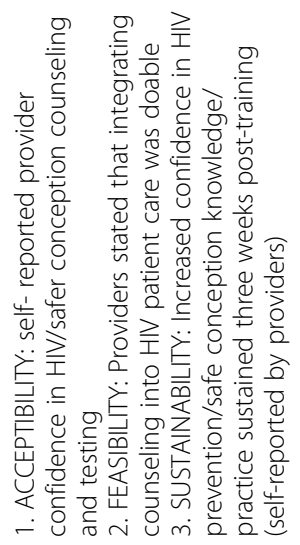

$\frac{\text { Iั }}{2}$

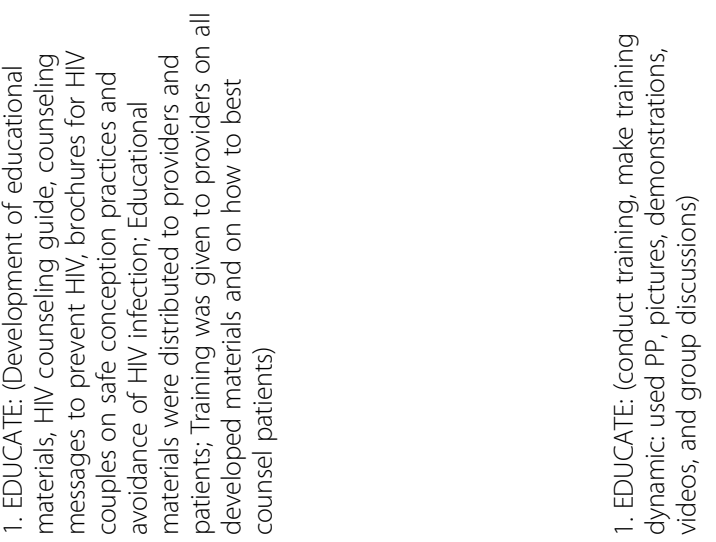

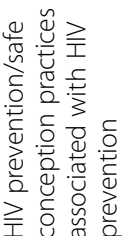

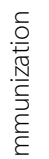

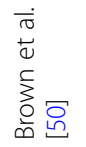

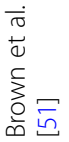




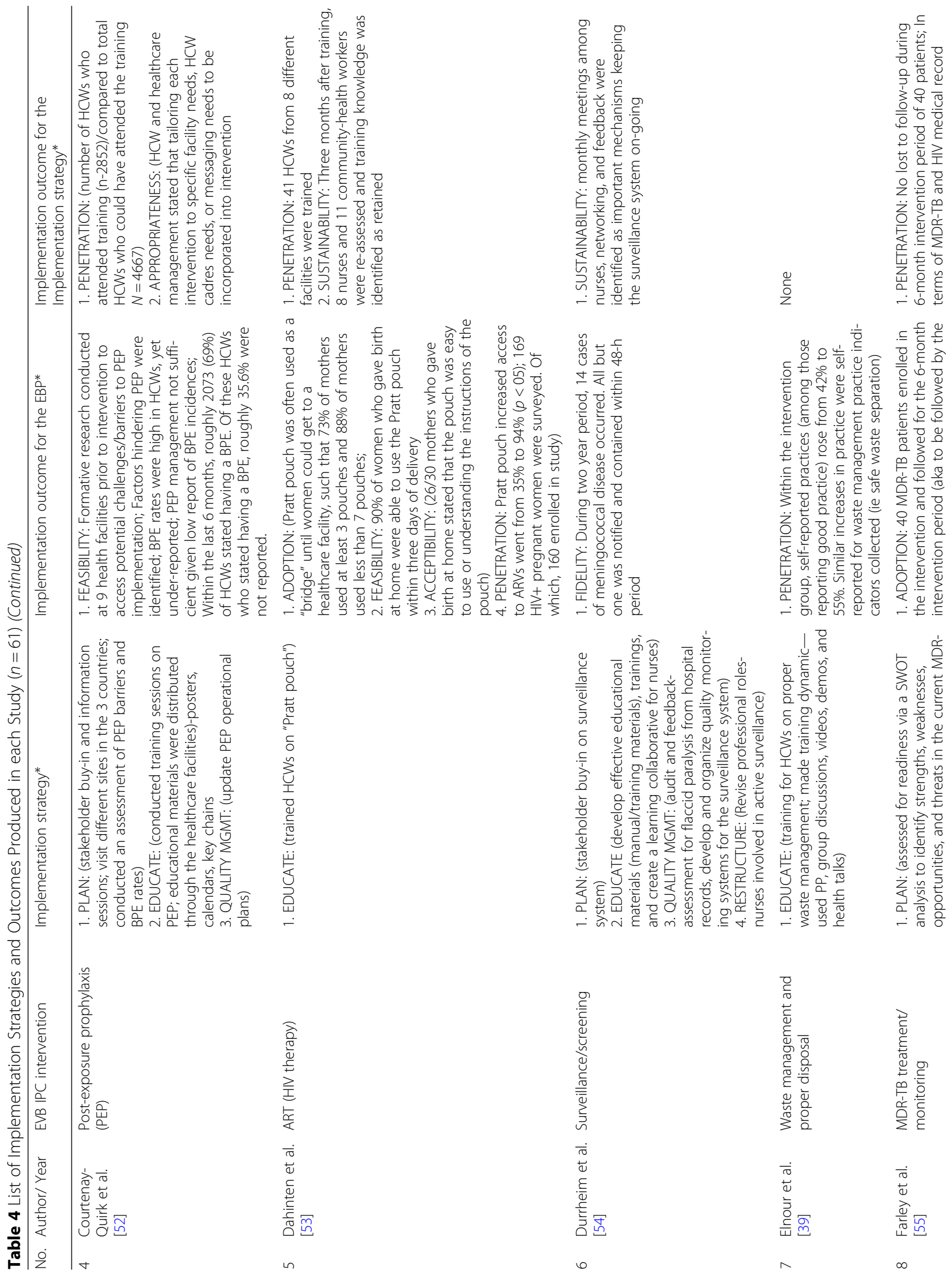




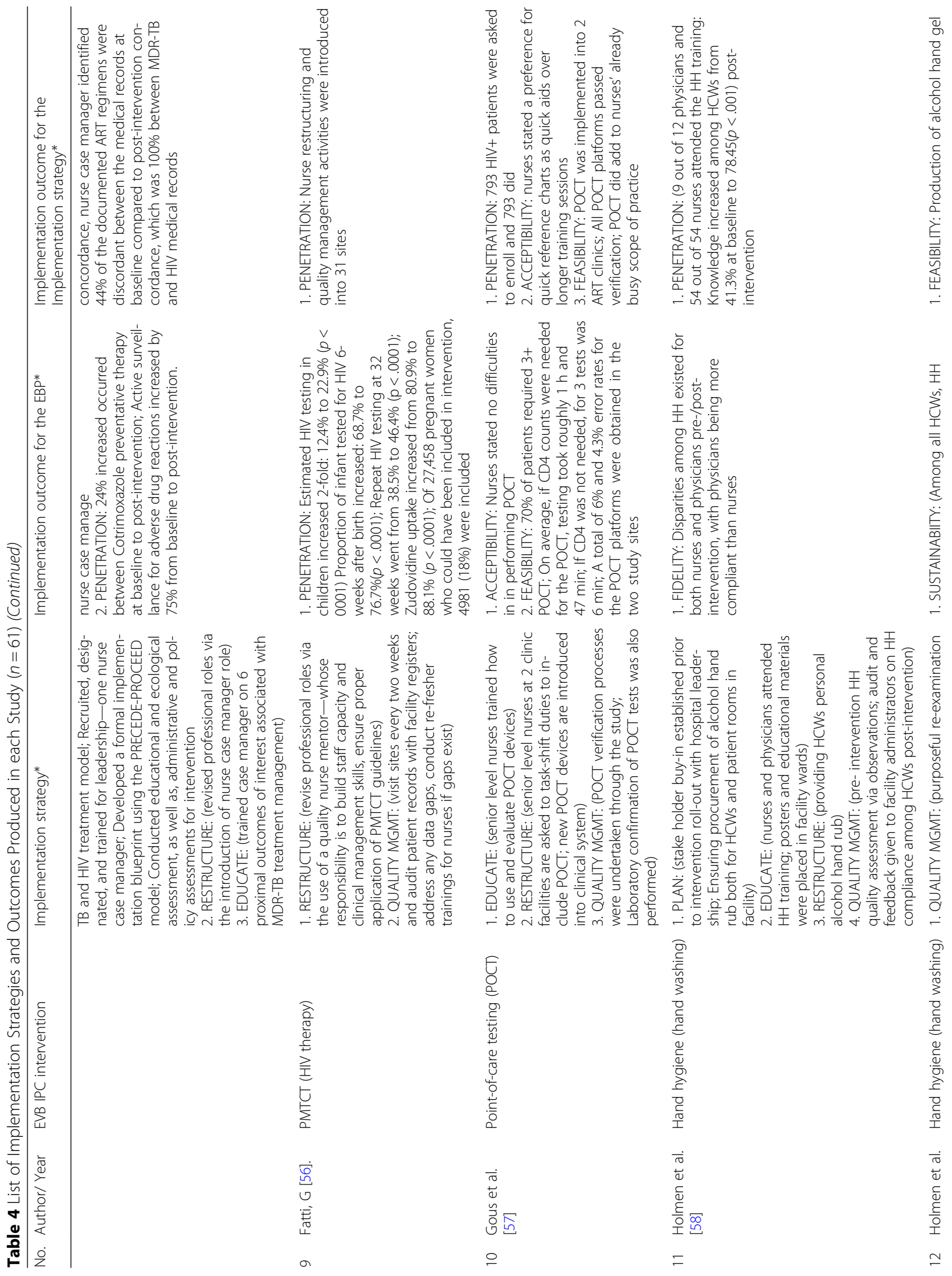




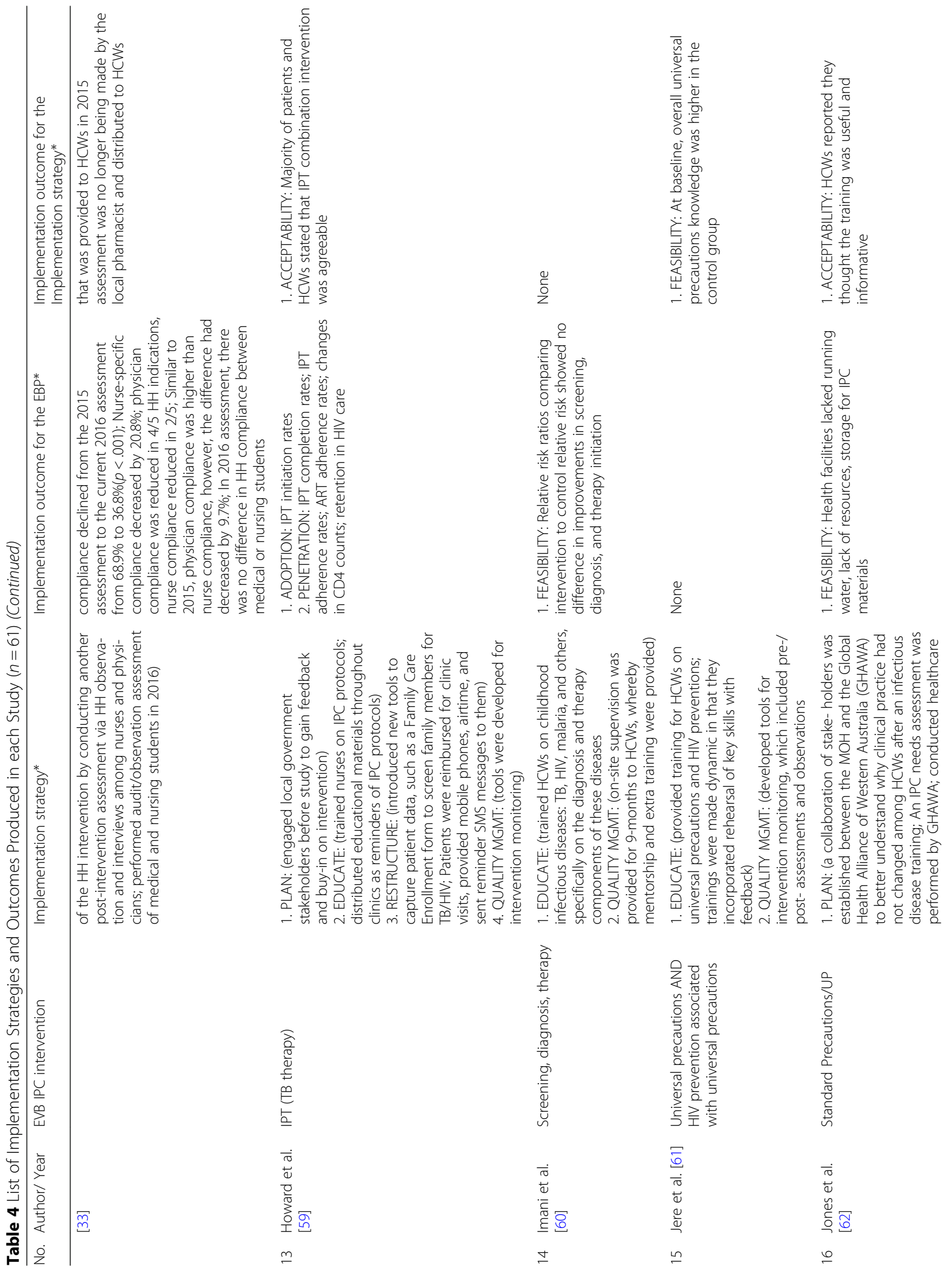




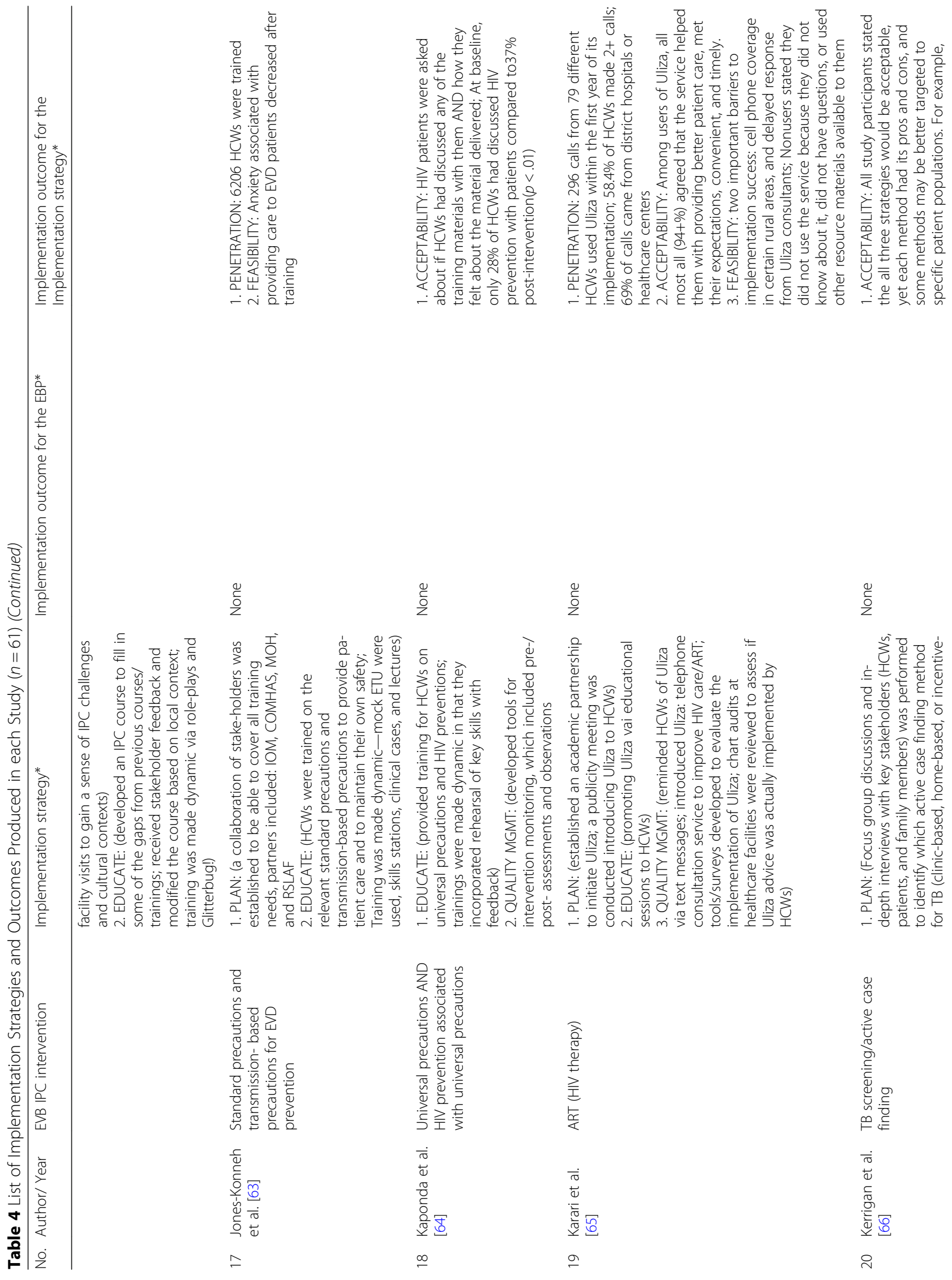




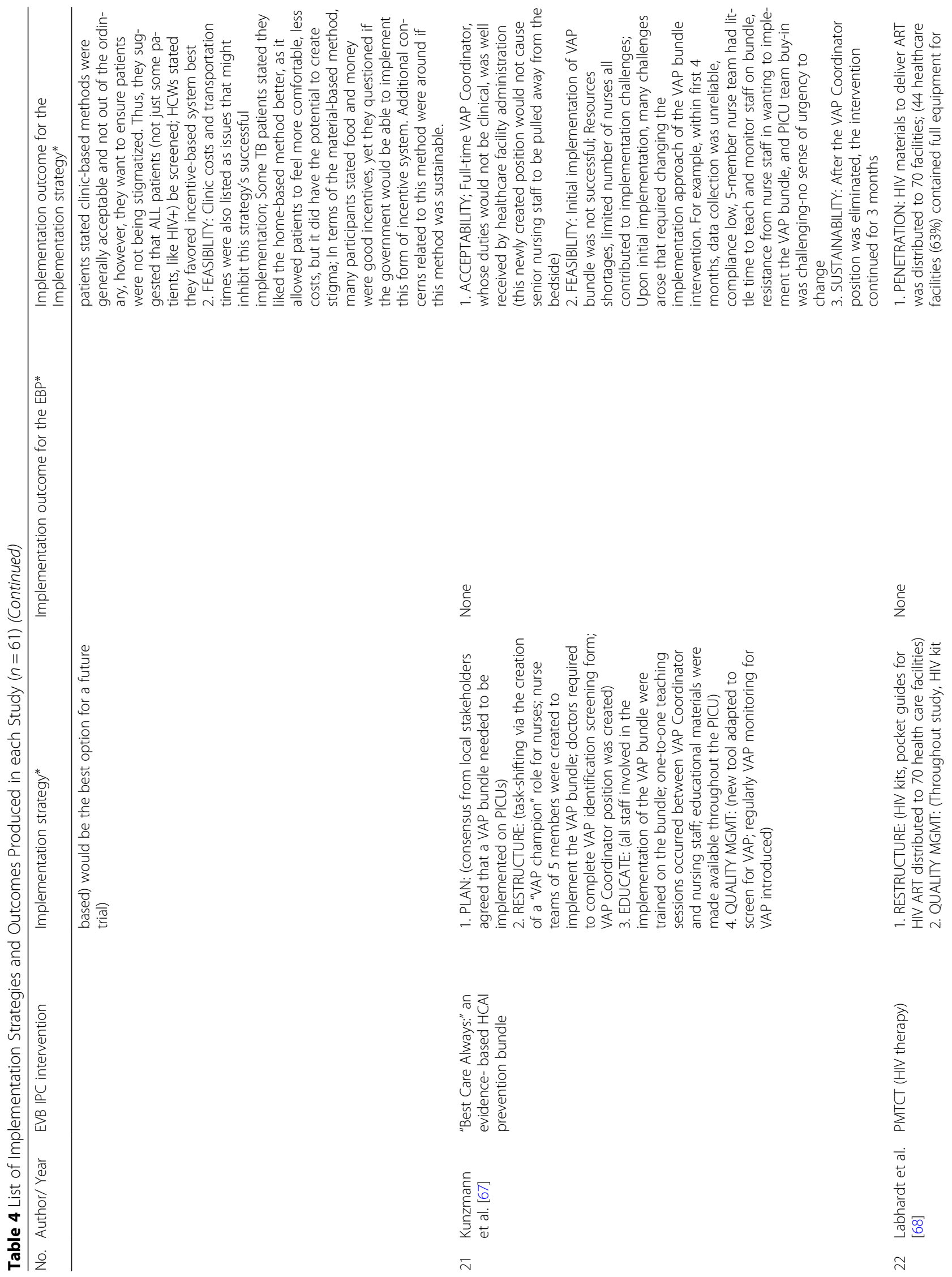




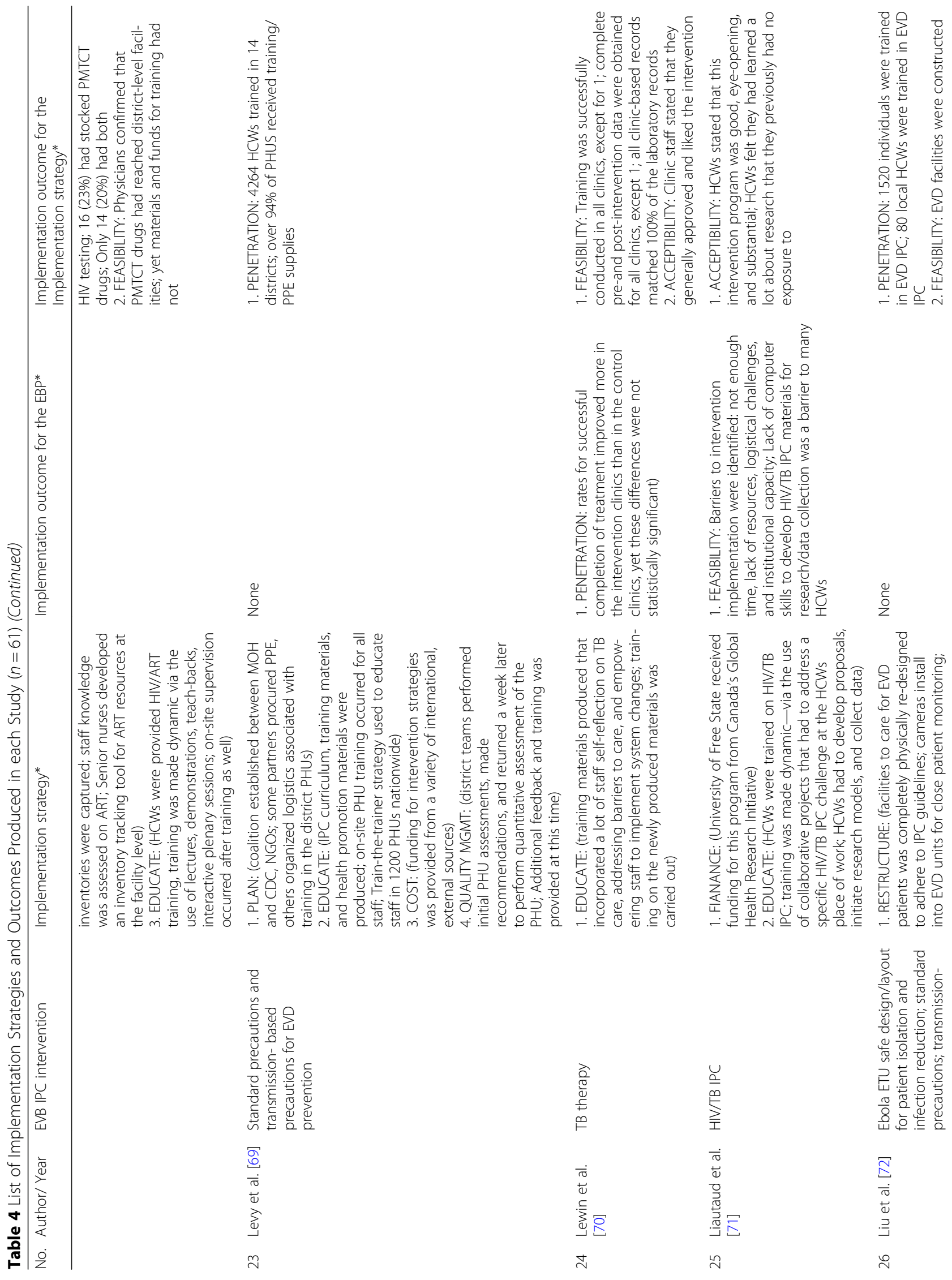




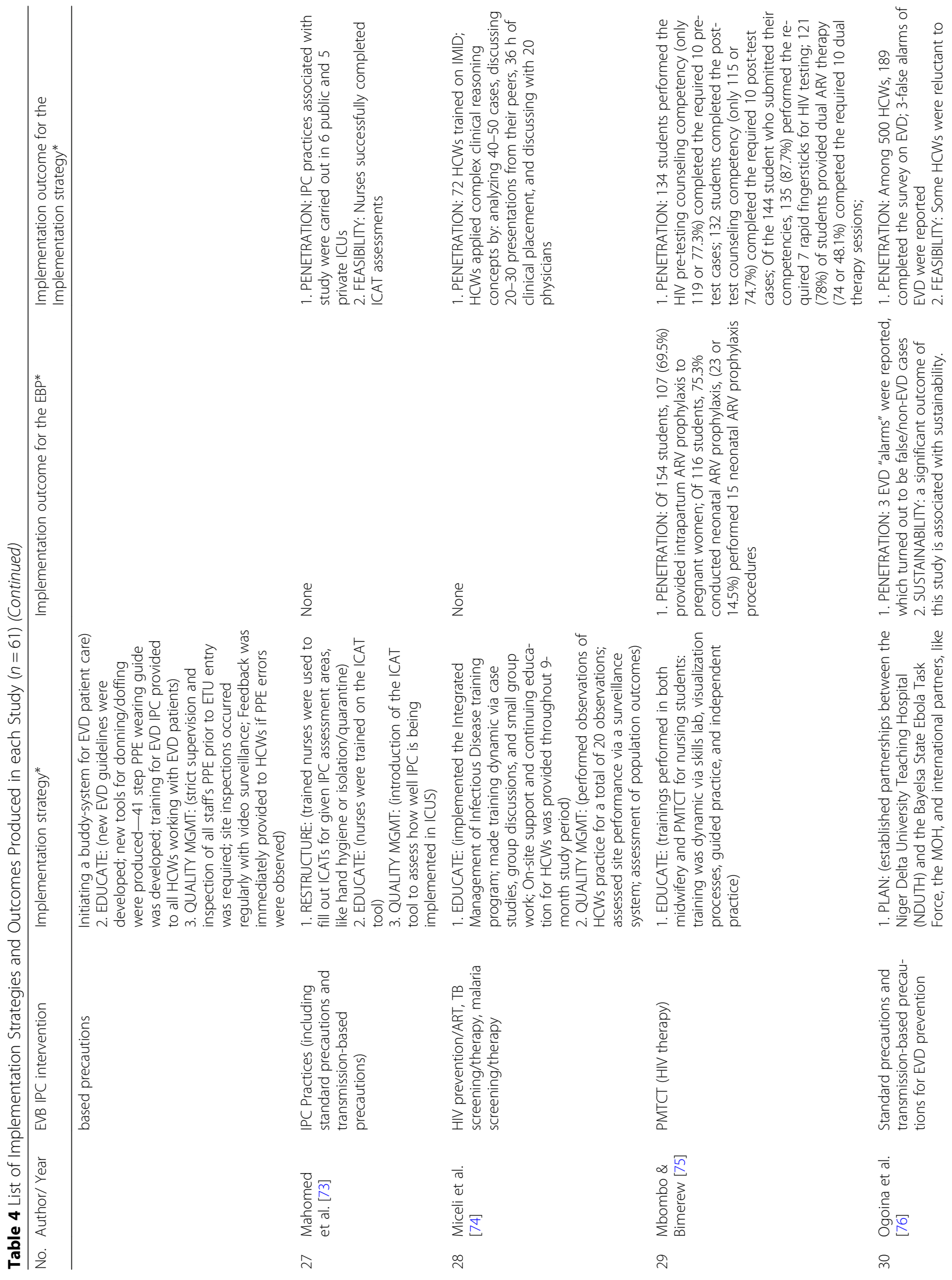




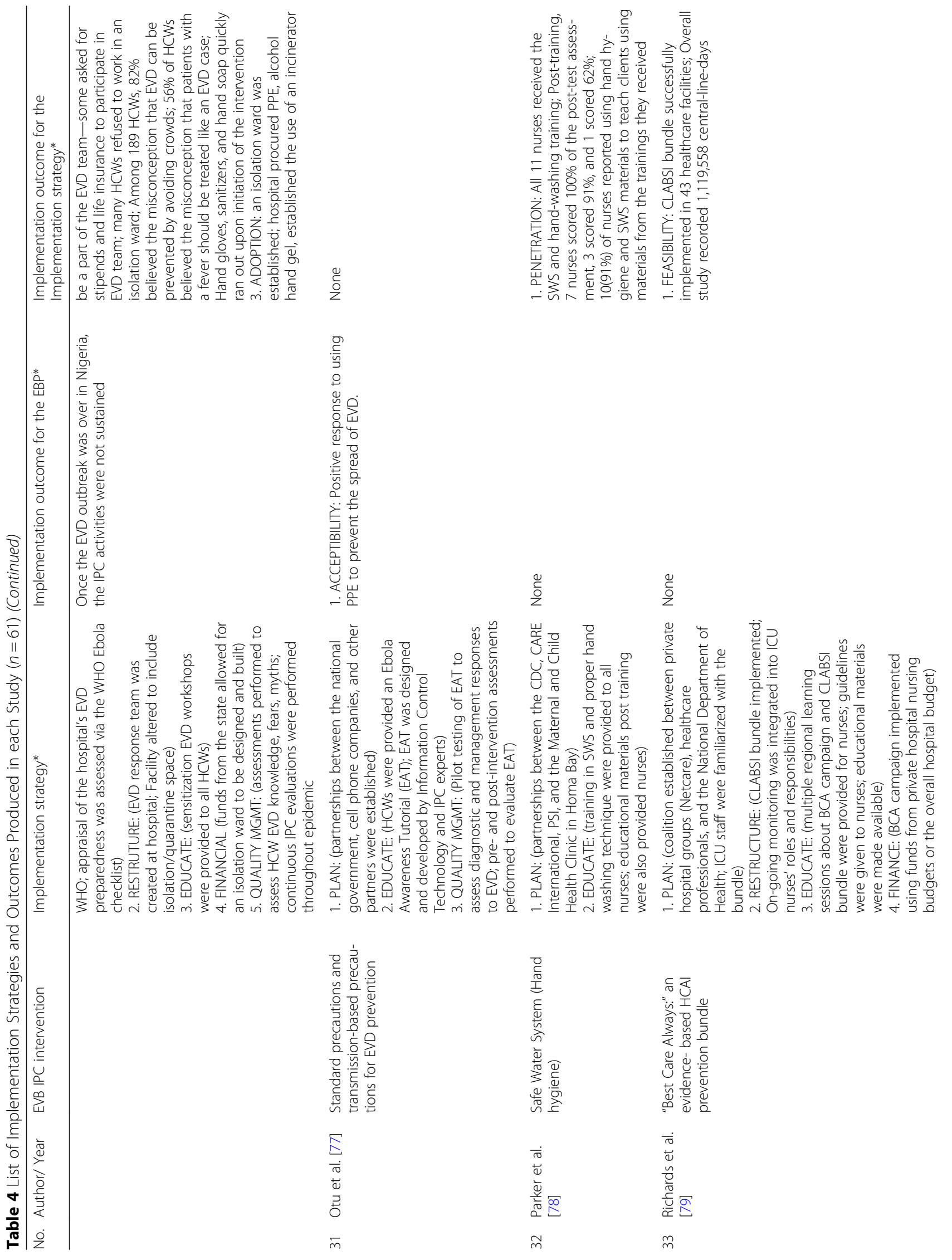



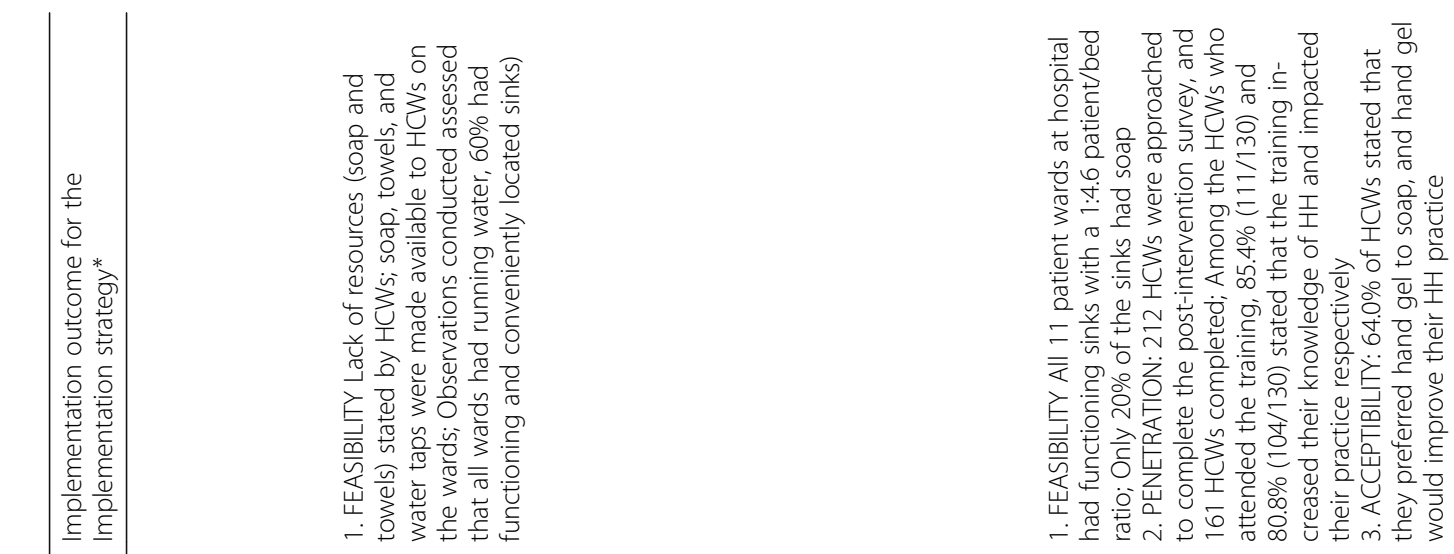

$\frac{\dddot{2}}{2}$

$\frac{\dddot{2}}{2}$

家

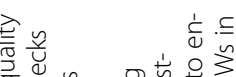

竞

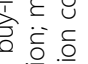

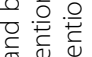

능

근 은

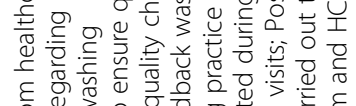

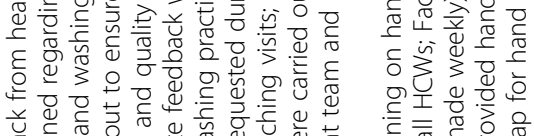

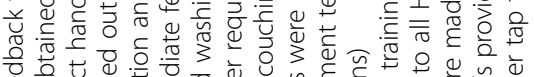

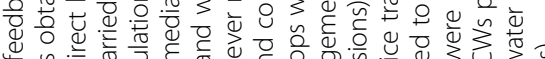

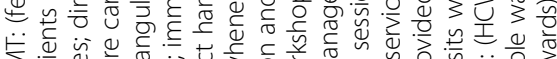

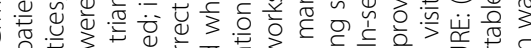

o

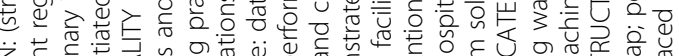

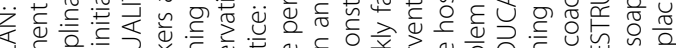

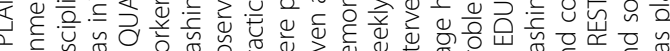

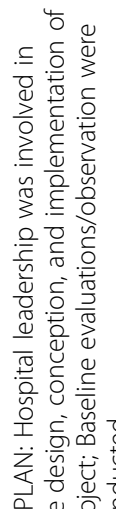

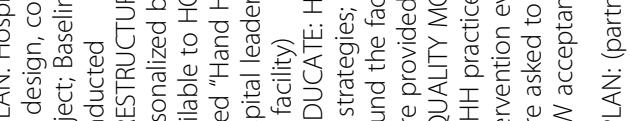

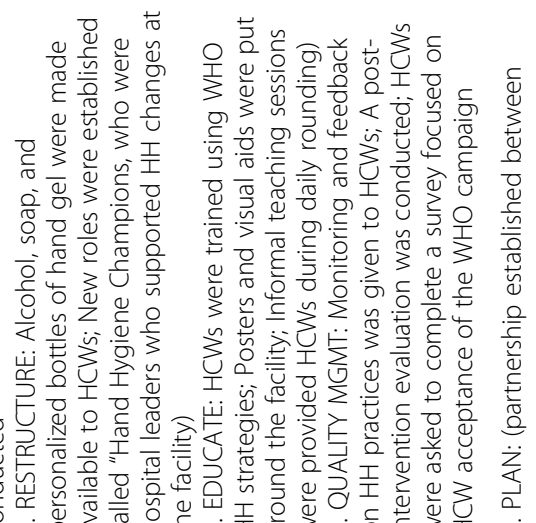

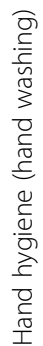

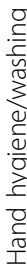

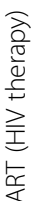

$\dot{\pi}$

点

$\frac{\frac{\circ}{n}}{\frac{0}{n}} \frac{\frac{0}{2}}{\frac{1}{n}}$

$\stackrel{m}{m}$ 


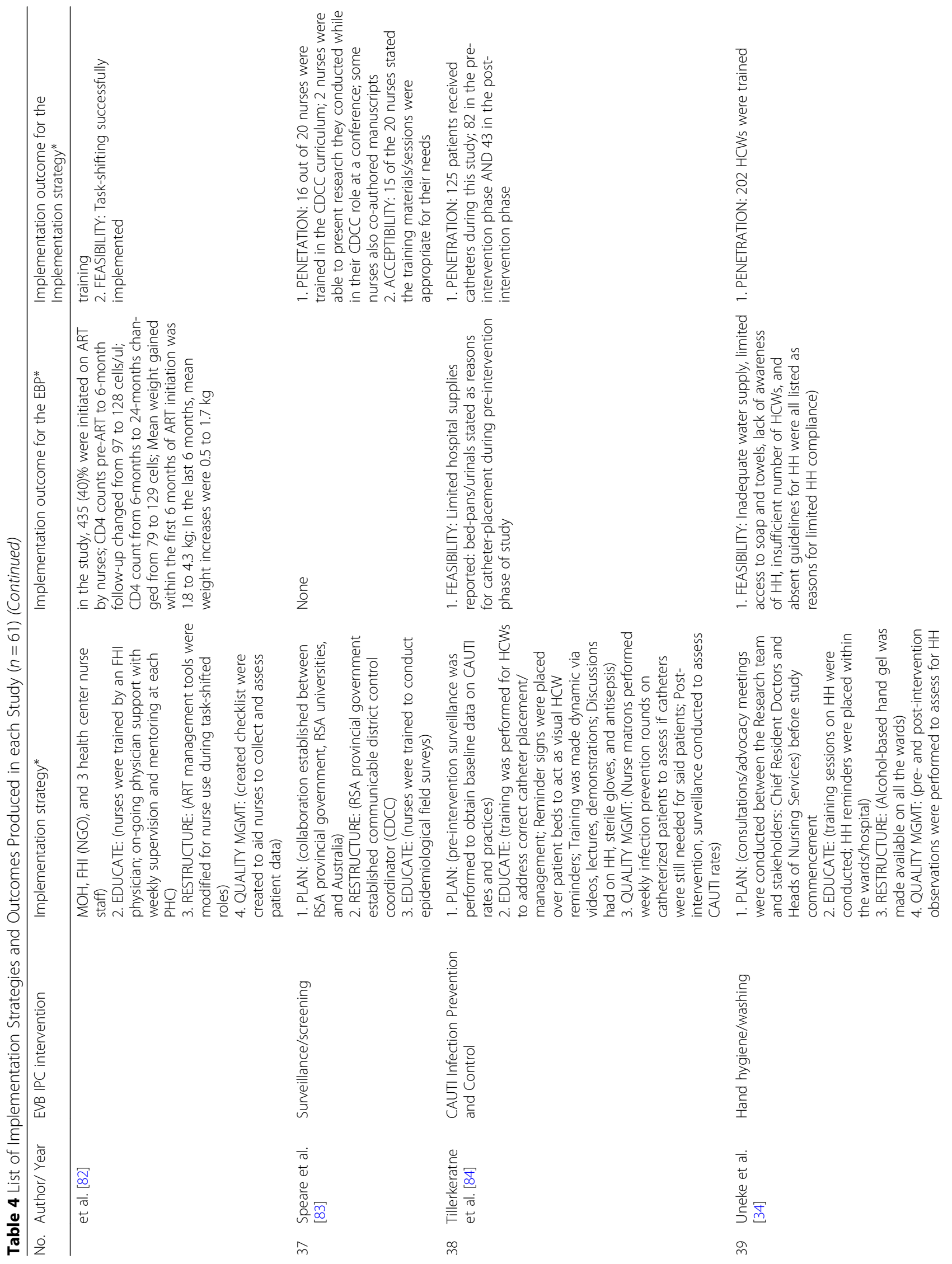




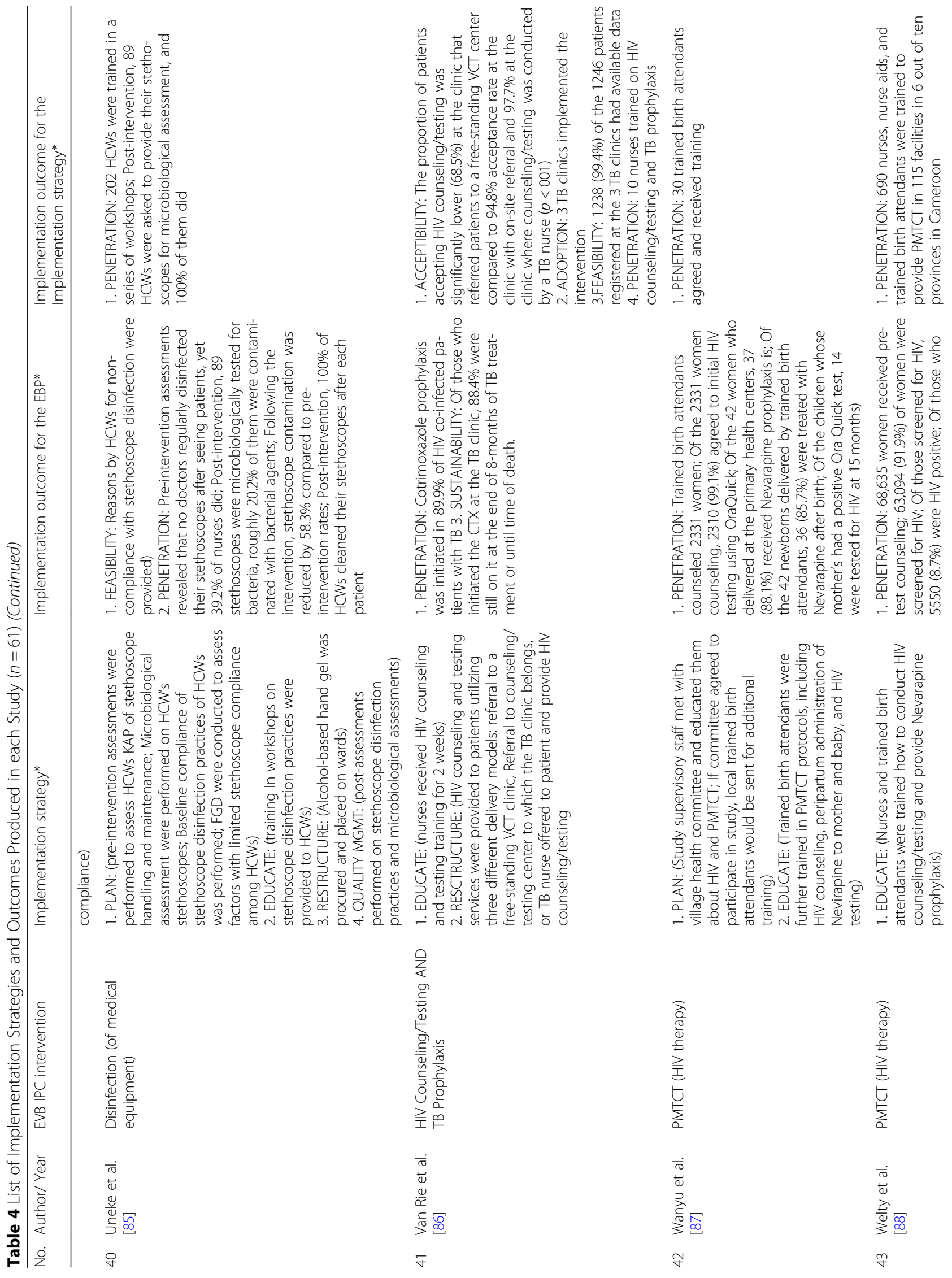




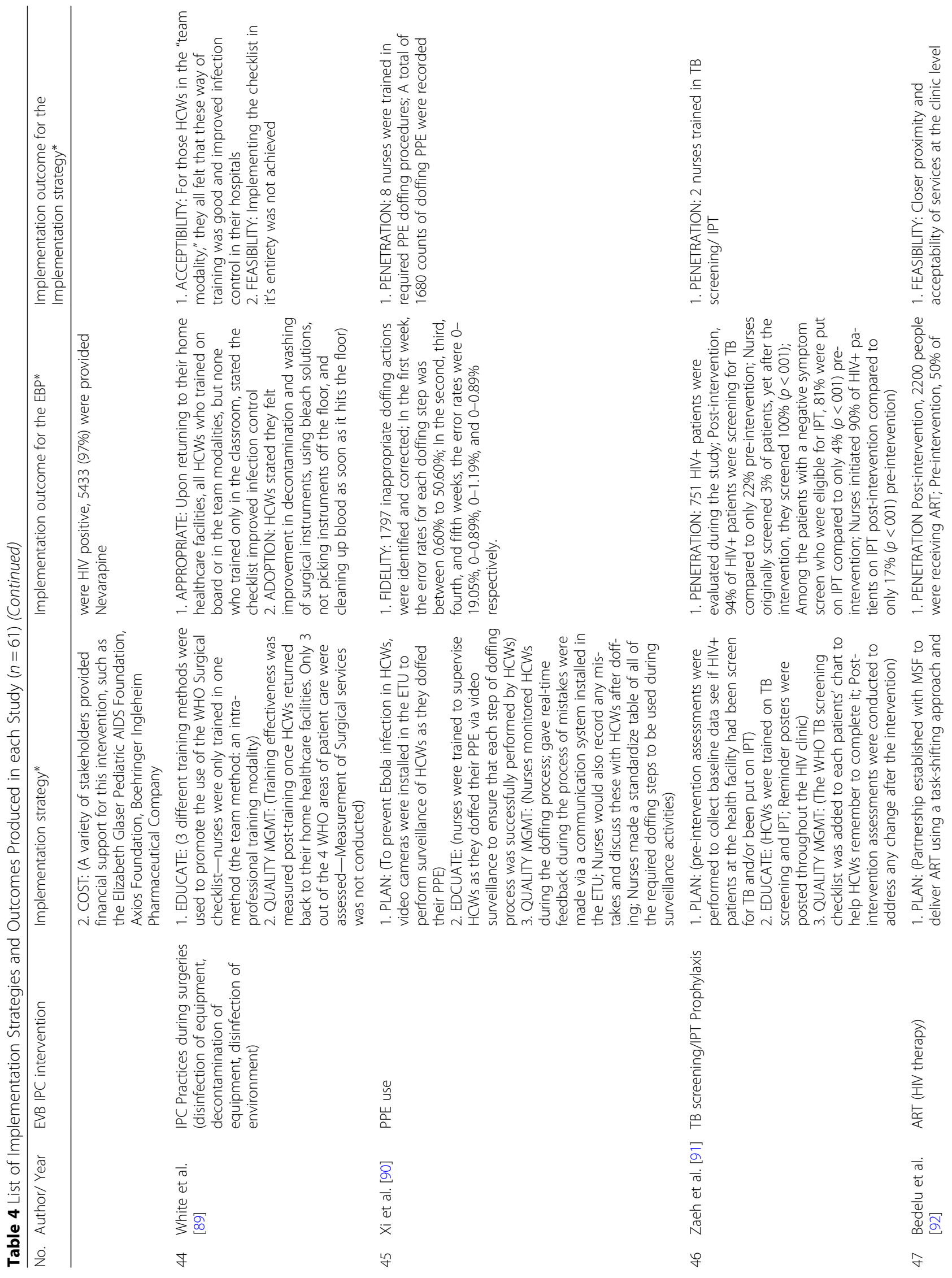




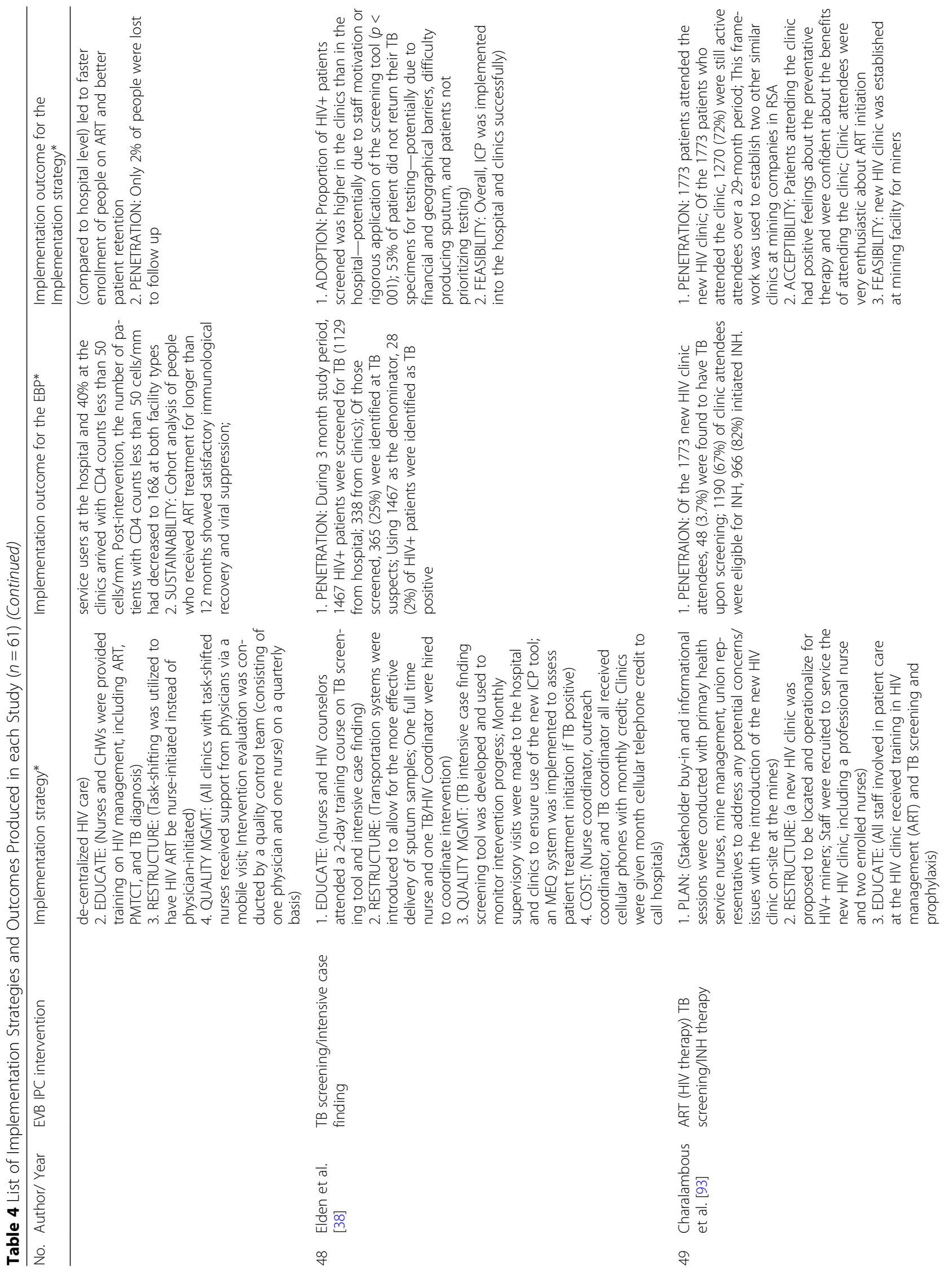




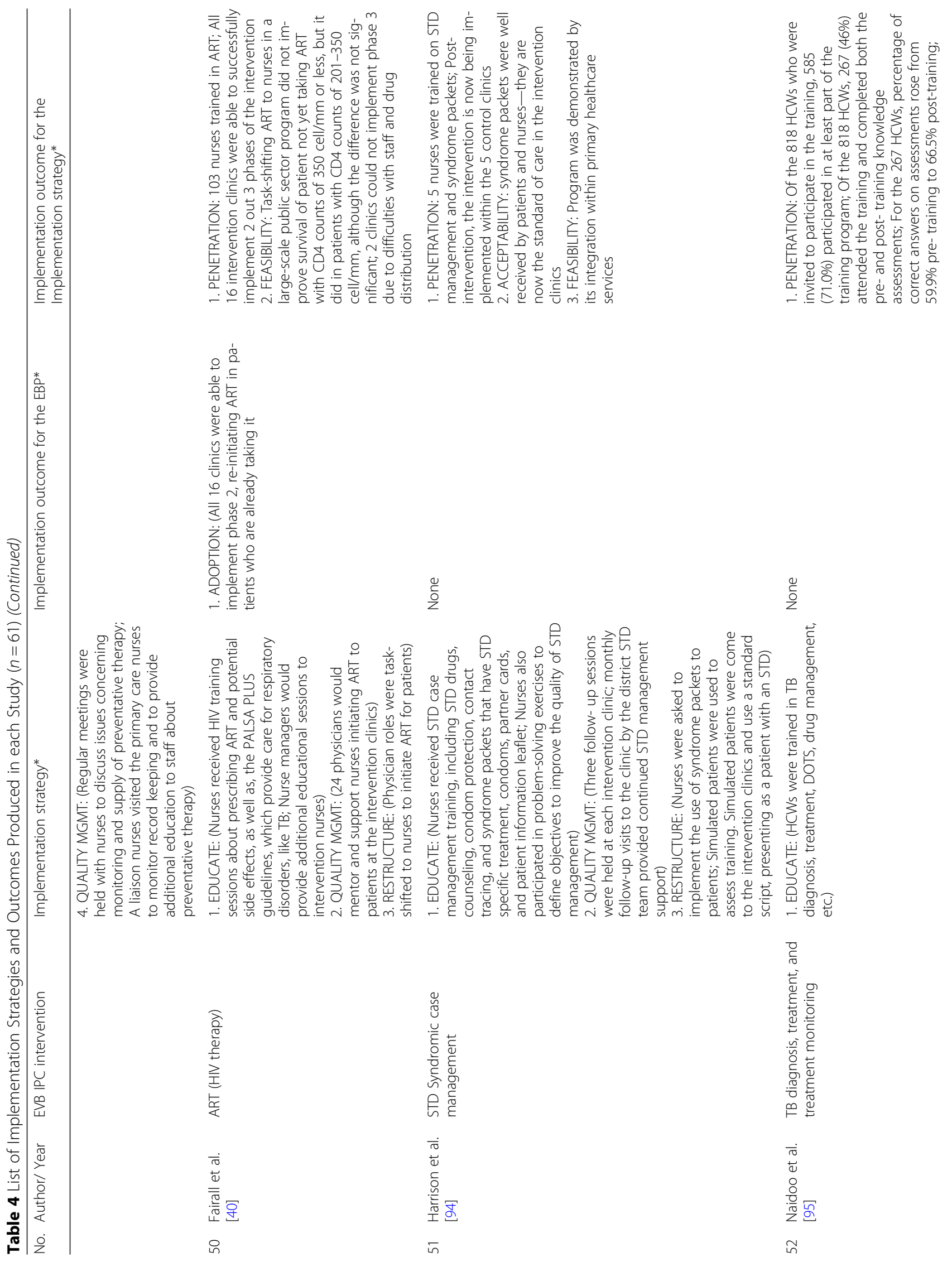




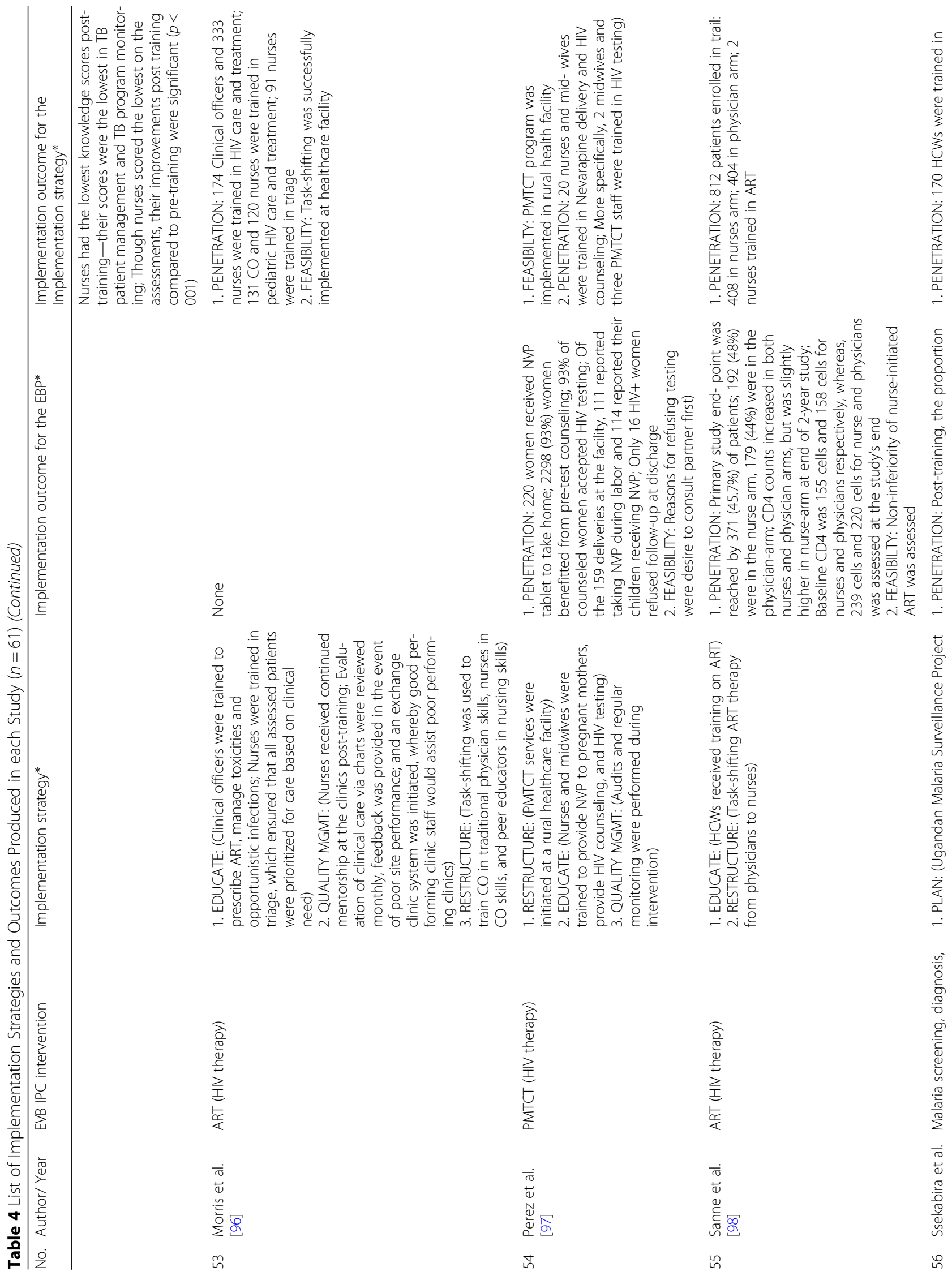




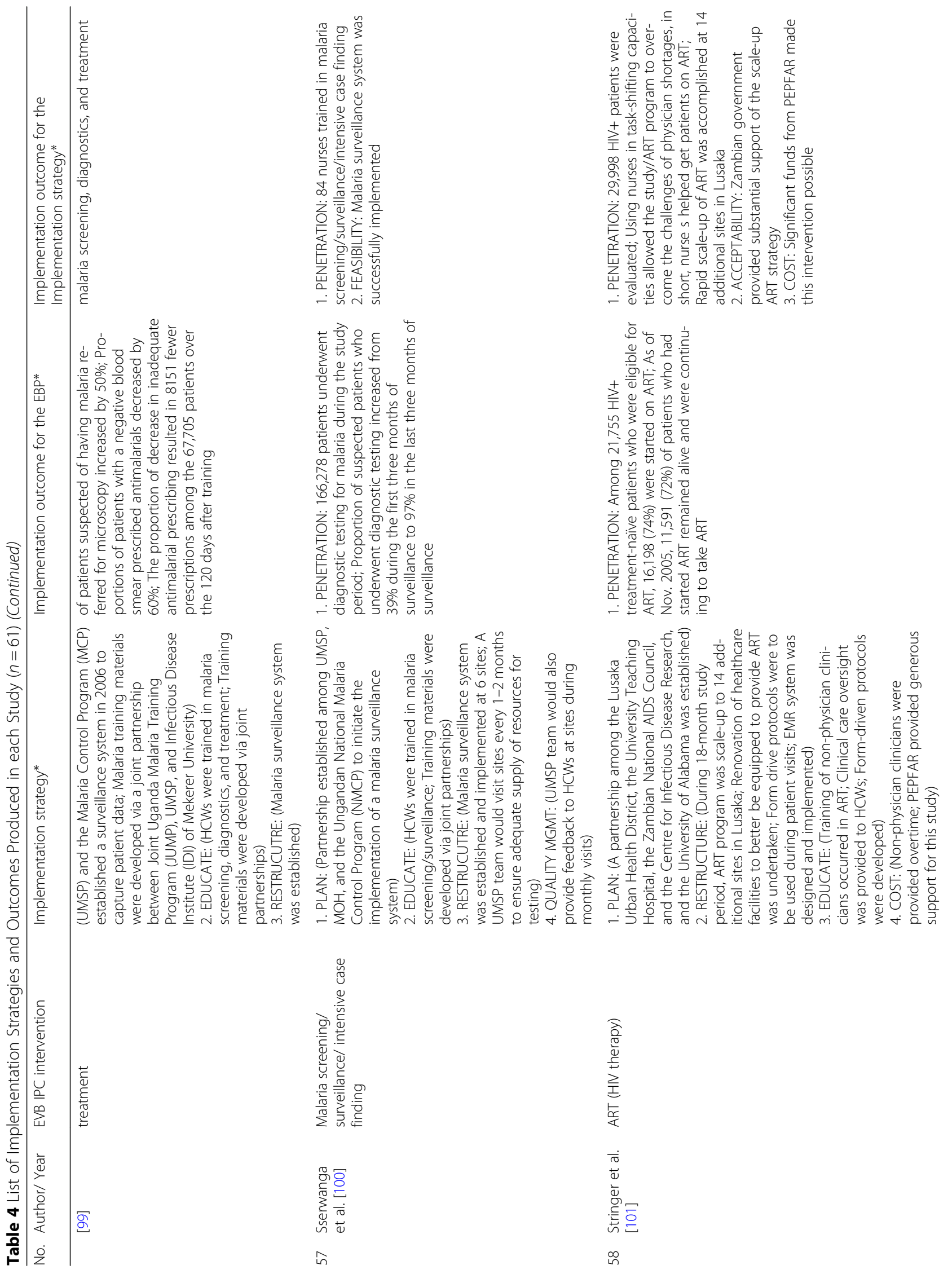




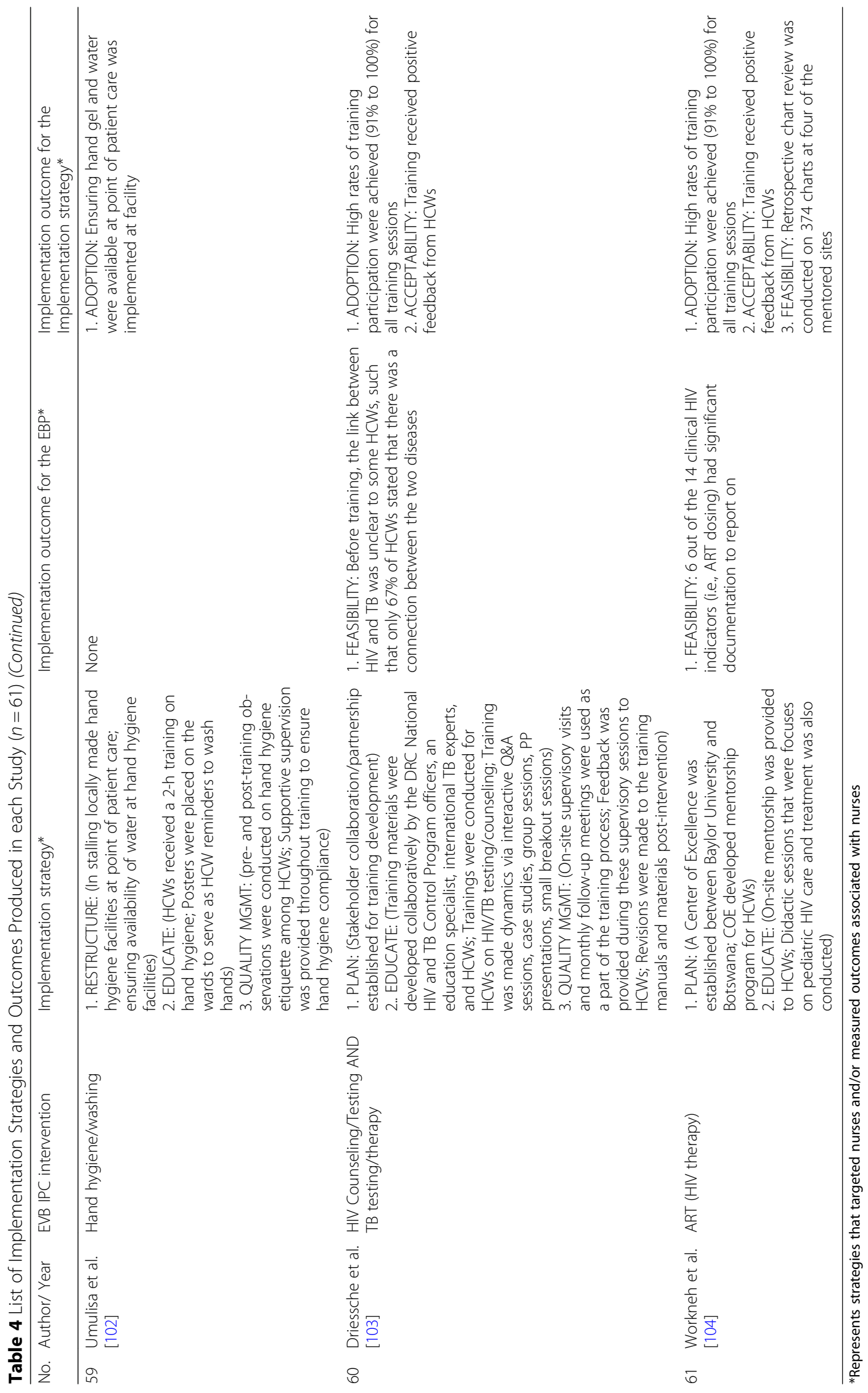


Table 5 Study characteristics associated with implementation strategies and outcomes for nurses and non-nurses ( $N=61)$

\begin{tabular}{|c|c|c|c|c|c|c|}
\hline & $\begin{array}{l}\text { Number } \\
\text { of } \\
\text { studies } \\
(n)\end{array}$ & $\begin{array}{l}\text { Percentage } \\
\text { of studies } \\
(\%)\end{array}$ & $\begin{array}{l}\text { Number of studies } \\
\text { with strategy/ } \\
\text { outcome focused } \\
\text { on nurses ( } n \text { ) }\end{array}$ & $\begin{array}{l}\text { Percentage of } \\
\text { studies with } \\
\text { strategy/outcome } \\
\text { focused on nurses } \\
(\%)\end{array}$ & $\begin{array}{l}\text { Number of studies with } \\
\text { strategy/outcome focused } \\
\text { on patients or overall health } \\
\text { system }(n)\end{array}$ & $\begin{array}{l}\text { Percentage of studies with } \\
\text { strategy/outcome focused } \\
\text { on patients or overall health } \\
\text { system (\%) }\end{array}$ \\
\hline \multicolumn{7}{|c|}{ Implementation strategies } \\
\hline Education & 59 & 96.7 & 58 & 95.1 & 1 & 1.6 \\
\hline $\begin{array}{l}\text { Quality } \\
\text { management }\end{array}$ & 39 & 63.9 & 21 & 34.4 & 18 & 29.5 \\
\hline Plan & 33 & 54.1 & 12 & 19.7 & 21 & 34.4 \\
\hline Restructure & 32 & 52.5 & 7 & 11.5 & 25 & 41.0 \\
\hline Finance & 8 & 13.1 & 2 & 3.3 & 6 & 9.8 \\
\hline Policy & 0 & 0.0 & 0 & 0.0 & 0 & 0.0 \\
\hline \multicolumn{7}{|c|}{ Implementation EBP outcomes } \\
\hline Penetration & 22 & 36.0 & 4 & 6.5 & 18 & 29.5 \\
\hline Feasibility & 13 & 21.3 & 6 & 9.8 & 7 & 11.5 \\
\hline Adoption & 5 & 8.2 & 1 & 1.6 & 4 & 6.6 \\
\hline Sustainability & 5 & 8.2 & 2 & 3.3 & 3 & 4.9 \\
\hline Acceptability & 4 & 6.6 & 3 & 4.9 & 1 & 1.6 \\
\hline Fidelity & 3 & 4.9 & 2 & 3.3 & 1 & 1.6 \\
\hline Appropriatene & 1 & 1.6 & 1 & 1.6 & 0 & 0.0 \\
\hline Cost & 0 & 0.0 & 0 & 0.0 & 0 & 0.0 \\
\hline $\begin{array}{l}\text { No EBP } \\
\text { outcome }\end{array}$ & 21 & 34.4 & na & na & na & na \\
\hline \multicolumn{7}{|c|}{ Implementation strategy outcomes } \\
\hline Penetration & 44 & 72.1 & 34 & 55.7 & 7 & 11.5 \\
\hline Feasibility & 28 & 45.9 & 6 & 9.8 & 22 & 36.1 \\
\hline Acceptability & 18 & 29.5 & 13 & 21.3 & 5 & 8.2 \\
\hline Adoption & 5 & 8.2 & 2 & 3.3 & 3 & 4.9 \\
\hline Sustainability & 3 & 4.9 & 3 & 4.9 & 0 & 0.0 \\
\hline Appropriatene & 2 & 3.3 & 2 & 3.3 & 0 & 0.0 \\
\hline Cost & 2 & 3.3 & 2 & 3.3 & 0 & 0.0 \\
\hline Fidelity & 0 & 0.0 & 0 & 0.0 & 0 & 0.0 \\
\hline $\begin{array}{l}\text { No strategy } \\
\text { outcome }\end{array}$ & 3 & 4.9 & na & na & na & na \\
\hline
\end{tabular}

\section{Implementation outcomes for implementation strategies}

The most common outcomes measured for implementation strategies used in this review were penetration and feasibility; a similar finding to the outcomes associated with EBPs. Forty-four (72\%) studies reported penetration. Thirty-four (56\%) and seven (12\%) studies reported penetration outcomes for nurses and non-nurses respectively (see Table 5). For nurses, penetration was most frequently used to measure the number of nurses experiencing or undergoing a given implementation strategy (e.g., number of nurses trained in hand hygiene). For the non-nurse category, penetration was used to scale-up patient services or measure loss to follow-up (see Table 5). Feasibility was measured in 28 (46\%) studies, with six (10\%) and $22(36 \%)$ studies measuring feasibility for nurses and non-nurses respectively. Feasibility measured if an IPC protocol could be successfully implemented for nurses. Four studies successfully implemented the WHO hand hygiene campaign to promote hand washing for healthcare workers [32, 58, 80, 81], demonstrating that the intervention could be implemented. Feasibility also described barriers to the successful implementation of an implementation strategy or to the procurement of resources for IPC protocol 
implementation. Soap, alcohol-based hand gels, and towels were procured for nurses to eliminate barriers related to hand disinfection, making it feasible for nurses to implement the EBP. The third most common outcome reported was acceptability $(n=18,30 \%)$. Acceptability was measured in 13 (21\%) and five (8\%) studies for nurses and non-nurses respectively (see Table 5). For nurses, this outcome measured nurses' opinions on the strategy and its utility. Five (8\%), three (55\%), and two (3\%) studies addressed adoption, sustainability, and appropriateness respectively. Sustainability captured nurses' ability to sustain knowledge acquired during a training for a defined period of time. Appropriateness measured nurses' perceptions of the cultural relevance of educational materials produced for a training or the benefit of training to the nursing profession. Cost, measured in only two (3\%) studies, captured the amount of funds provided from the development sector to ensure that implementation strategies were carried out. Zero (0\%) studies measured fidelity to implementation strategies.

\section{Quality appraisal}

All studies $(n=61,100 \%)$ included within this review met the pre-determined or global quality criteria. Only one study, which was a multi-modal study, had a score under the cut-off criteria for its quantitative section. The qualitative score for this study met criteria, and thus was included in the review, which adhered to the predetermined criteria for multi-model studies. Fifty-five studies $(90 \%)$ were quantitative or multi-modal studies. The most common MAStARI score was $5(n=19,31 \%)$. The structure of the MAStaRI scales favors experimental designs; five articles with MAStARI scores of 9 or higher were randomized controlled trials. Three (4.9\%) studies were purely qualitative, both examining the feasibility of an EBP implementation strategy. Three (4.9\%) studies were mixed methods, and both achieved MMAT rating of $50 \%$ or higher.

\section{Discussion}

Infectious diseases contribute significantly to patient and healthcare worker morbidity and mortality in SSA. Nurses who engage in direct patient care are at increased risk of nosocomial and other infections [22, 105]. To address these HAI challenges, many IPC EBPs have been deployed at the healthcare facility level. Yet, obstacles within LMICs make it difficult to sustain these practices. Implementation science provides an opportunity to identify and execute strategies that may better sustain EBPs over time [106]. Based on the results of this review, it is clear that implementation of IPC EBPs in SSA requires additional research, practice, and funding. More research from an explicit implementation sciencespecific perspective is needed for the following reasons:
(1) very few of the studies in this review were able to produce sustainable outcomes, a potential limitation of the strategies implemented. Yet, more research is needed to know if this is true or not. (2) All studies in this review, except for one, did not identify as an implementation study. Thus, the strategies were not measured using implementation science definitions for strategies. Therefore, increased implementation science research into which, what combination, and in what specific context implementation strategies should be used in SSA is important to advance the science and to fully reap the potential of IPC protocols to save the lives of patients and healthcare workers in vulnerable regions.

Despite increased risk of contracting infectious diseases, nurses were underrepresented in the studies in this review. The majority of studies did not exclusively focus on nurses; they focused on non-nurse participants, including physicians, patients, auxiliary hospital staff, or some other aspect of the healthcare system, and nurses were included in the samples as generic healthcare workers. In studies where nurses were the target population, the numbers of nurses included in the study was often not reported or too low to draw generalizable conclusions. Given this finding, a shift is needed in global health research to properly determine what IPC EBP practices are best suited for nurse implementation at health facilities in SSA, especially as the tasks of nurses are different from other healthcare workers. Whereas there can be some lessons learned from other healthcare cohorts, the scope of practice for nurses, as it relates to IPC, is vastly different from other healthcare workers. While many different types of health care workers (including laboratory technicians and water and sanitation staff) are at increased risk of acquiring HAIs, this study focused on nurses for the following reasons: (a) nurses have unique needs (they spend the most amount of time with patients than any other health worker and operate in highly unstandardized and variable circumstances); (b) nurses are by far the largest cadre of the workers in SSA (even though their needs often take second place or are lumped to those of physicians). As infectious diseases evolve and become more prevalent, EBPS for IPC will become an increasingly important part of nurses' scope of practice. Thus, additional and better-quality research that targets the unique IPC EBP challenges of the different healthcare worker cohorts, especially nurses and their involvement in IPC efforts, are needed.

Standard and transmission-based precautions were underemphasized in this review; most studies focused on administrative precautions. Standard precautions represent standard care. Therefore, an IPC study without a standard precautions component overlooked a critical component of IPC. Transmission-based precautions are typically undertaken when a patient is already diseased 
and to prevent further disease. Very few studies focused on this specific set of IPC EBPs, despite the fact that so many diseases in SSA, like TB, require them. Based on the results of this review, transmission-based and standard precautions are not sufficiently studied within LMICs, leaving a significant gap in the IPC literature.

The implementation strategies identified in this review lacked diversity. Of the seven implementation strategies identified, the predominant method was nurse education, specifically training on an IPC protocol. Johnson et al. [107] found similar results in a systematic review assessing implementation strategies for cervical cancer in SSA. Rowe et al. [108] argue that training in conjunction with other strategies (i.e., group problem solving, management techniques, supervision, and sound infrastructures) could improve healthcare worker practices in LMICs. Implementation science, along with other disciplines, acknowledges that access to information alone is not sufficient to produce long-term change [109]. Education only strategies are not likely to produce sustainable IPC knowledge or practice change among nurses. In addition to a lack of diversity in implementation strategies, there were notable gaps: policy and finance strategies, which play an important role in overall implementation, were rarely utilized. Unfortunately, the degree to which these strategies influence each other and other strategies (i.e., quality management) is relatively unknown given gaps in implementation science literature.

Among the studies in this review, it was identified that implementation strategies for nurses compared to nonnurses are vastly different. Education and quality management strategies are predominately used for nurses, and planning and restructure strategies are most often used for non-nurses. Nurses are trained and undergo regular monitoring, whereas non-nurses, especially patients, benefit from restructured clinical services and planned healthcare activities. Additional scholarship is needed to affirm if these strategies are indeed the best for each population.

Studies in this review that utilized multi-faceted implementation strategies produced better outcomes (such as feasibility, acceptability, etc.) compared to their singlestrategy counterparts; a finding consistent with the current implementation science literature [110]. A comprehensive implementation approach, addressing potential challenges at each level of a healthcare system, yields stronger and more sustainable outcomes. Training, an educational strategy, and real-time audit/feedback, a quality management strategy, produced better outcomes when used together than alone [54]. More specifically, hand hygiene rates increased $(8.0 \%$ to $21 \%, p<.001)$ when multiple strategies (quality management, education, planning) were used to promote this EBP, whereas hand hygiene rates declined $(68.9 \%$ to $36.8 \%, p<.001$ ) when only one strategy was used (quality management) [32, 33]. Multi-faceted strategies also generally focus on more than one stakeholder. Many of the studies in this review that used multi-faceted strategies targeted patients and healthcare workers. Single strategies focused on patient outcomes, perpetuating the underrepresentation of nurses, and overlooking nurse outcomes. Restructure is an excellent example of single strategy utilization. Most restructure strategies involved taskshifting nurse duties; however, this strategy is geared toward patient care and the impact on patient care, not the impact on the nurse practice. To advance implementation research within the global health context, multifaceted strategies need to be promoted and better metrics need to be developed to capture outcomes related to multi-faceted approaches [111].

Many studies only reported on implementation strategy outcomes, not EBP outcomes. Two possible explanations for this finding are as follows: (1) most EBPs are already accepted as effective practices that do not require additional validation, and (2) measuring EBPs is challenging in a LMIC. Collecting data on an implemented strategy is fairly easy. Collecting and verifying EBP data is a significant undertaking in resourceconstrained settings. However, implementation science research conducted in SSA must focus on some of the lesser reported outcomes, like cost or sustainability. Although these outcomes are more challenging to measure and require more time and funding to capture, implementation science studies that do not report on these outcomes have missed an opportunity to inform healthcare practices and policies at a macro-level.

Implementation outcomes measured for nurses compared to non-nurses are distinct. More EBP outcomes were measured for non-nurses, and more strategy outcomes were measured for nurses. The results of this review suggest that the relationship between EBP outcomes and non-nurses, specifically patients, may be related to how an EBP is defined. EBPs are "the conscientious, explicit and judicious use of current best evidence in making decisions about the care of the individual patient." [112]. Patients, not nurses, are at the center of EBPs, which may explain the observed relationship between EBP outcomes and non-nurses. Educating patients is at the heart of the nursing profession; however, nurses need access to specific IPC EBPs information that is unique to them. Within global health, a common reality is that there are too few nurses to provide patient care. Investing in nurses and their safety must start to be a priority of the global community. If sources of inertia around nurse investment are not addressed within LMICs, then entire global communities will continue to suffer poor health as a result. 
Studies with similar implementation strategies often used similar outcomes to measure impact. For example, the implementation of education interventions was often measured using an indicator of penetration (e.g., a training is implemented and researchers measured number of nurses trained). Similarly, planning strategies measured stakeholder response to an intervention. These outcomes were often not informative. A potential reason for this limited outcome data is related to the funding mechanisms of global health research and the types of outcomes that donors prioritize. The development sector is primarily interested in penetration outcomes (i.e., counts or proportions of nurses trained). In LMICs, purchasing resources for a project or building a new health facility is relatively achievable. It is much harder to ensure that resources and expertise are being used appropriately, health facilities have an adequate number of staff, and that overall operations of these facilities are sustainable. The "collect and measure what is easiest" notion is not going to improve the promotion of IPC EPBs in LMICs. Different outcome-strategy combinations need to be researched, allowing for increased growth of the implementation science discipline and increased IPC innovation in LMICs.

This review is not without limitations. The overall quality of the studies in this review was highly variable. Many studies were inadequately designed to capture outcomes of interest, biased, or were neither generalizable nor reproducible. Many studies only reported descriptive statistics. Many studies poorly described their methodologies. Additionally, most of the studies in this review were only just above the cut-off criteria for inclusion.

\section{Conclusion}

This review provides evidence that additional research from an implementation science-specific perspective is needed to promote IPC protocols for nurses in SSA. While many of the studies included in this review did not frame their methods or outcomes as implementationfocused, they indeed were. Implementation science should be fostered and promoted in global health. While many IPC EBPs are well-known, the best strategies to successfully implement them remains undetermined for LMICs. Implementation science has a unique opportunity to expand scholarship around best implementation practices in SSA. For example, a better understanding of which strategies are best suited for specific contexts or phenomena in SSA, like an infectious disease epidemic, to promote IPC protocols is needed. In short, additional implementation science research could greatly contribute to the limited knowledge base around which strategies should be utilized at the onset and during an infectious disease epidemic to promote IPC protocols and keep nurses from becoming patients during these emergency situations. Furthermore, implementation science-specific research could also alter the way scholarship in SSA is prioritized and funded, especially as it pertains to development mechanisms. Given the region's reliance on foreign assistance to cover healthcare expenditures [113], implementation science, with an emphasis on cost and policy, could identify investments for SSA and its healthcare workers.

Prevention is a critical component of infection control. The cost of IPC inaction is large. For the countries most affected by Ebola in 2014 (Sierra Leone, Liberia, and Guinea), economic modeling projections for postepidemic healthcare strengthening initiatives estimate the cost of reconstruction to be US $\$ 877$ million in 2018 [114]. These funds are necessary for infrastructure and service delivery changes, including IPC measures. With a stronger health system able to withstand a future epidemic, the loss of life, particularly of nurses, during the 2014 outbreak may have been avoided. With emerging infections currently challenging the global community, like the EVD epidemic in the DRC and Marburg virus identified in Sierra Leone for the first time [115], neglecting IPC prevention strategies, especially for nurses, is unaffordable.

\section{Supplementary information}

Supplementary information accompanies this paper at https://doi.org/10. 1186/s13012-019-0958-3.

Additional file 1. Key Search Terms and Search Results by Search Engine. (DOCX $20 \mathrm{~kb}$ )

\section{Abbreviations}

ART: Antiretroviral therapy; DALY: Disability-adjusted life year; EBP: Evidencebased practice; EVD: Ebola viral disease; HCAl: Healthcare-associated infections; IPC: Infection Prevention and Control; JBI: Joanna Briggs Institute; LMIC: Low-middle-income country; MAStARI: Meta-analysis for Statistics Assessment and Review Instrument; MMAT: Mixed methods appraisal tool; PRISMA: Preferred Reporting Items for Systematic Review and Meta-Analysis; SSA: Sub-Saharan Africa; TB: Tuberculosis; WHO: World Health Organization

\section{Authors' contributions}

$A E B C, K A R$, JES, and $A B$ made substantial contributions to this systematic review. AEBC and KAR completed the database search, screened all studies for review inclusion, and appraised all studies for quality using the JBI framework. A third reviewer (JES) also appraised a random sample of $20 \%$ $(n=20)$ of the total articles in the review. Data extraction was conducted by the primary reviewer (AEBC) for all articles. All authors contributed to the writing and revising of the final manuscript. All authors read and approved the final manuscript.

\section{Funding}

At the time of this review, AEBC was supported by the Hillman Scholars Program in Nursing Innovation Predoctoral Fellowship; KAR was supported by the Robert Wood Johnson Foundation Predoctoral Fellowship.

\section{Availability of data and materials}

All data generated, produced, or analyzed for this study are included in this published article (including within supplementary files).

Ethics approval and consent to participate Not applicable. 


\section{Consent for publication}

Not applicable.

\section{Competing interests}

The authors declare that they have no competing interests.

Received: 1 February 2019 Accepted: 2 December 2019 Published online: 30 December 2019

\section{References}

1. Murray CJL, Lopez AD. Mortality by cause for eight regions of the world: global burden of disease study. Lancet. 1997;349(9061):1269-76.

2. World Health Organization. The top ten causes of death. Geneva: WHO; 2018. [cited 2018 July 28]. Available from: http://www.who.int/en/newsroom/fact-sheets/detail/the-top-10-causes-of-death

3. Institute for Health Metrics and Evaluation HDN, The World Bank. The global burden of disease: generating evidence, guiding policy_Sub-Saharan African regional edition. Seattle: IHME; 2013.

4. World Health Organization. Atlas of the African health statistics. Geneva: WHO; 2017.

5. World Health Organization. Disability-adjusted life years (DALYS) by region. Geneva: WHO; 2019. [cited 2018 July 28]. Available from: https://www.who. int/gho/mortality_burden_disease/daly_rates/text/en/

6. Economic growth in Africa rebounds, but not fast enough [press release]. World Bank Group 2018.

7. Awumbila M. Drivers of migration and urbanization in Africa: key trends and issues. New York: United Nations; 2017.

8. Lohnert B. Migration and the rural-urban transition in sub-Saharan Africa. Berlin, Germany: Humboldt Universitat zu Berlin; 2017.

9. Centers for Disease Control. Cost of the Ebola epidemic. Atlanta: CDC; 2016. [updated 2016 Aug 8; cited 2018 Sept 20]. Available from: https://www.cdc. gov/vhf/ebola/history/2014-2016-outbreak/cost-of-ebola.html\#N1

10. Centers for Disease Control. 40 years of Ebola viral disease around the world. Atlanta: CDC; 2018. [updated 2018 Aug 18;cited 2018 Sept 21]. Available from: https://www.cdc.gov/vhf/ebola/history/chronology.html

11. Collier P, Stereck O, Manning R. The moral and fiscal implications of antiretroviral therapies for HIV in Africa. Oxford: Univeristy of Oxford; 2015.

12. World Health Organization. Ebola viral disease. Democratic republic of the Congo: external situation report 21. Geneva: WHO; 2018.

13. World Health Organization. Report on the burden of endemic health care-associated infection worldwide-clean care is safer care. Geneva: WHO; 2011.

14. Nejad SB, Allegranzi B, Syed SB, Ellis B, Pittet D. Health-care-associated infection in Africa: a systematic review. Bull World Health Organ. 2011; 89(10):757-65

15. Centers for Disease Control. Types of healthcare associated infections. Atlanta: CDC; 2014. [updated 2018 Mar 26;cited 2018 Sept 20]. Available from: https://www.cdc.gov/hai/infectiontypes.html

16. Office of Disease Prevention and Health Promotion. Healthcare-associated infections: an overview: ODPHP; 2019. [updated 2019 Jan 1;cited 2018 Sept 22]. Available from: https://health.gov/hcq/prevent-hai.asp

17. Joshi R, Reingold A, Menzies D, Pai M. Tuberculosis among health-care workers in low- and middle-income countries: a systematic review. PLoS Med. 2006;3(12):e494.

18. Rothe C, Schlaich C, Thompson S. Healthcare-associated infections in subSaharan Africa. J Hosp Infect. 2013;85(4):257-67.

19. Butler R, Monsalve M, Thomas G, Herman T, Segre A, Polgreen P, et al. Estimating time physicians and other health care workers spend with patients in an intensive care unit using a sensor network. Am J Med. 2018; 131(8):e9-e15.

20. World Health Organization. Health worker Ebola infections in Guinea, Liberia and Sierra Leone: a preliminary report. Geneva: WHO; 2015.

21. Alele FO, Franklin RC, Emeto TI, Leggat P. Occupational tuberculosis in healthcare workers in sub-Saharan Africa: a systematic review. Arch Environ Occup Health. 2018:1-14. Available from: https://www.ncbi.nlm.nih.gov/ pubmed/29702035

22. Uden L, Barber E, Ford N, Cooke GS. Risk of tuberculosis infection and disease for health care workers: an updated meta-analysis. Open Forum Infect Dis. 2017;4(3):137.
23. World Health Organization. Infection prevention and control. Geneva: WHO; 2018. [cited 2018 July 28]. Available from: http://www.who.int/infectionprevention/en/

24. World health Organization. Guidelines on core components of infection prevention and control programmes at the national and acute health care facility level. Geneva: WHO; 2016.

25. Centers for Disease Control. Infection control basics. Atlanta: CDC; 2016. [updated 2017 Feb 10;cited 2018 July 26]. Available from: https://www.cdc. gov/infectioncontrol/basics/index.html

26. Centers for Disease Control. Standard precautions for all patients. Atlanta: CDC; 2017. [updated 2017 Jan 16;cited 2018 July 21]. Available from: https:// www.cdc.gov/infectioncontrol/basics/standard-precautions.html

27. Centers for Disease Control. Infection control in healthcare settings. Atlanta: CDC; 2016. [cited 2018 Sept 21]. Available from: https://www.cdc.gov/tb/ topic/infectioncontrol/default.htm

28. Barrera E, Livchits $V$, Nardell E. F-A-S-T: a refocused, intensified, administrative tuberculosis transmission control strategy. Int J Tuberc Lung Dis. 2015;19(4):381-4.

29. Nathavitharana RR, Daru P, Barrera AE, Mostofa Kamal SM, Islam S, UI-Alam $M$, et al. FAST implementation in Bangladesh: high frequency of unsuspected tuberculosis justifies challenges of scale-up. Int J Tuberc Lung Dis. 2017;21(9):1020-5

30. Dharmadhikari AS, Mphahlele M, Venter K, Stoltz A, Mathebula R, Masotla T, et al. Rapid impact of effective treatment on transmission of multidrugresistant tuberculosis. Int J Tuberc Lung Dis. 2014;18(9):1019-25.

31. United Nations. Global strategy for women's and children's health. New York: UN; 2010.

32. Allegranzi B, Sax H, Bengaly L, Richet H, Minta DK, Chraiti MN, et al. Successful implementation of the World Health Organization hand hygiene improvement strategy in a referral hospital in Mali, Africa. Infect Control Hosp Epidemiol. 2010;31(2):133-41.

33. Holmen IC, Niyokwizerwa D, Nyiranzayisaba B, Singer T, Safdar N. Challenges to sustainability of hand hygiene at a rural hospital in Rwanda. Am J Infect Control. 2017:45(8):855-9.

34. Uneke CJ, Ndukwe CD, Oyibo PG, Nwakpu KO, Nnabu RC, Prasopa-Plaizier N Promotion of hand hygiene strengthening initiative in a Nigerian teaching hospital: implication for improved patient safety in low-income health facilities. Braz J Infect Dis. 2014;18(1):21-7.

35. Ridde $V$. Need for more and better implementation science in global health BMJ Glob Health. 2016;1(2):e000115.

36. Proctor EK, Powell BJ, McMillian JC. Implementation strategies: recommendations for specifying and reporting. Implement Sci. 2013;8:139.

37. Boulle A, Kouanfack C, Laborde-Balen G, Carrieri MP, Donstop M, Boyer S, et al. Task shifting HIV care in rural district hospitals in Cameroon: evidence of comparable antiretroviral treatment-related outcomes between nurses and physicians in the Stratall ANRS/ESTHER trial. J Acquir Immune Defc Syndr. 2012;62(5):569-76.

38. Elden S, Lawes T, Kudsk-Iversen S, Vandelanotte J, Nkawanyana S, Welfare W, et al. Integrating intensified case finding of tuberculosis into HIV care: an evaluation from rural Swaziland. BMC Health Serv Res. 2011;11:118.

39. Elnour A, Mohamed Reda Moussa M, El-Borgy MD, Fadelella N, Mahmoud $\mathrm{AH}$. Impacts of health education on knowledge and practice of hospital staff with regard to healthcare waste management at White Nile state main hospitals, Sudan. Int J Health Sci. 2015;9(3):315-31.

40. Fairall L, Bachmann MO, Lombard C, Timmerman V, Uebel K, Zwarenstein M et al. Task shifting of antiretroviral treatment from doctors to primary-care nurses in South Africa (STRETCH): a pragmatic, parallel, cluster-randomised trial. Lancet. 2012;380(9845):889-98.

41. Proctor E, Silmere H, Raghavan R, Hovmand P, Aarons G, Bunger A, et al. Outcomes for implementation research: conceptual distinctions, measurement challenges, and research agenda. Adm Policy Ment Health. 2011;38(2):65-76.

42. Proctor EK, Landsverk J, Aarons G, Chambers D, Glisson C, Mittman B. Implementation research in mental health services: an emerging science with conceptual, methodological, and training challenges. Adm Policy Ment Health. 2009;36(1):24-34.

43. Whittemore R, Knafl K. The integrative review: updated methodology. J Adv Nurs. 2005;52(2):546-53.

44. Liberati A, Altman DG, Tetzlaff J, Mulrow C, Gotzsche PC, loannidis JP, et al. The PRISMA statement for reporting systematic reviews and meta-analyses of studies that evaluate health care interventions: explanation and elaboration. PLoS Med. 2009;6(7):e1000100. 
45. Powell BJ, Waltz TJ, Chinman MJ, Damschroder LJ, Smith JL, Matthieu MM, et al. A refined compilation of implementation strategies: results from the expert recommendations for implementing change (ERIC) project. Implement Sci. 2015;10:21.

46. Joanna Briggs Institutute. The Joanna Briggs approach. South Australia: Univeristy of Adelaide; 2018. [cited 2018 July 29]. Available from: http:// joannabriggs.org/jbi-approach.html

47. Joanna Briggs Institutute. Critical appraisal tools. South Australia: University of Adelaide; 2018. [cited 2018 July 28]. Available from: http://joannabriggs. org/research/critical-appraisal-tools.html

48. Munn Z, Porritt K, Lockwood C, Aromataris E, Pearson A. Establishing confidence in the output of qualitative research synthesis: the ConQual approach. BMJ Med Res Methodol. 2014;14:108.

49. Pluye P, Robert E, Cargo M, Bartlett G, O'Cathain A, Griffiths F, et al. Proposal: a mixed methods appraisal tool for systematic mixed studies reviews. Montreal: McGill University; 2011. [Available from: http://mixedmethodsappraisaltoolpublic pbworks.com/w/file/fetch/84371689/MMAT\%202011\%20criteria\%20and\%2 Otutorial\%202011-06-29updated2014.08.21.pdf

50. Brown J, Njoroge B, Akama E, Breitnauer B, Leddy A, Darbes L, et al. A novel safer conception counseling toolkit for the prevention of HIV: a mixed-methods ealuation in Kisumu, Kenya. AIDS Educ Prev. 2016;28(6): 524-38

51. Brown V, Oluwatosin O, Ogundeji M. Impact of training intervention on immunization providers' knowledge and practice of routine immunization in Ibadan, South-Western Nigeria: a primary health care experience. Pan Afr 996 Med J. 2017;26(1):216

52. Courtenay-Quirk C, Selenic D, Lahuerta M, Kassa G, Murrman M, Bock N. Development of an intervention to increase occupational postexposure prophylaxis in Sub-Saharan Africa. J Assoc Nurses AIDS Care. 2016;27(5):727-30.

53. Dahinten AP, Malkin RA. The Pratt pouch provides a three-fold access increase to antiretroviral medication for births outside health facilities in southern Zambia. Open Biomed Eng J. 2016;10:12-8.

54. Durrheim D, Harris B, Speare R, Billinghurst K. The use of hospital-based nurses for the surveillance of potential disease outbreaks. Bull World Health Organ. 2001;78(1):22-7.

55. Farley JE, Kelly AM, Reiser K, Brown M, Kub J, Davis JG, et al. Development and evaluation of a pilot nurse case management model to address multidrug-resistant tuberculosis (MDR-TB) and HIV in South Africa. PLoS One. 2014;9(11):e111702.

56. Fatti G, Rundare A, Pududu B, Mothibi E, Jason A, Shaikh N, et al. An innovative approach to improve the quality of prevention of mother-tochild transmission of HIV programs through nurse clinical mentoring in South Africa. J Acquir Immune Defc Syndr. 2013;63(2):e76-e8.

57. Gous N, Scott L, Potgieter J, Natbeni L, Sanne I, Stevens W. Implementation of multiple point-of-care testing in 2 HIV antiretroviral treatment clinics in South Africa. J Acquir Immune Defc Syndr. 2016;71(2):e34-43.

58. Holmen IC, Seneza C, Nyiranzayisaba B, Nyiringabo V, Bienfait M, Safdar N Improving hand hygiene practices in a rural hospital in Sub-Saharan Africa. Infect Control Hosp Epidemiol. 2016;37(7):834-9.

59. Howard AA, Hirsch-Moverman Y, Saito S, Gadisa T, Daftary A, Melaku Z. The ENRICH study to evaluate the effectiveness of a combination intervention package to improve isoniazid preventive therapy initiation, adherence and completion among people living with HIV in Ethiopia: rationale and design of a mixed methods cluster randomized trial. Contemp Clin Trials Commun. 2017;6:46-54.

60. Imani P, Jakech B, Kirunda I, Mbonye MK, Naikoba S, Weaver MR. Effect of integrated infectious disease training and on-site support on the management of childhood illnesses in Uganda: a cluster randomized trial. BMC Pediatr. 2015;15:103.

61. Jere DL, Kaponda CP, Chimwaza A, Crittenden KS, Kachingwe SI, McCreary LL, et al. Improving universal precautions and client teaching for rural health workers: a peer-group intervention. AIDS Care. 2010; 22(5):649-57.

62. Jones M, Gower S, Whitfield A, Thomas S. Evaluation of practice change in Tanzanian health professionals 12 months after participation in an infection prevention and management course. J Infect Prev. 2015;16(5):200-6.

63. Jones-Konneh TEC, Murakami A, Sasaki H, Egawa S. Intensive education of health care workers improves the outcome of Ebola virus disease: lessons learned from the 2014 outbreak in Sierra Leone. J Exp Med. 2017;243(2):101-5.

64. Kaponda C, Jere D, Chimwaza A, Crittenden K, Kachingwe S, Norr J, et al. Impacts of a peer group intervention on occupation-related behaviors for urban hospital workers in Malawi. J Assoc Nurses AIDS Care. 2009;20(4):293-307.
65. Karari C, Tittle R, Penner J, Kulzer J, Bukusi EA, Marima R, et al. Evaluating the uptake, acceptability, and effectiveness of Uliza! clinicians' HIV hotline: a telephone consultation service in Kenya. Telemed J E Health. 2011;17(6):420-6.

66. Kerrigan D, West N, Tudor C, Hanrahan CF, Lebina L, Msandiwa R, et al. Improving active case finding for tuberculosis in South Africa: informing innovative implementation approaches in the context of the Kharitode trial through formative research. Health Res Policy Syst. 2017;15(1):42.

67. Kunzmann H, Dimitrades K, Morrow B, Argent A. Reducing paediatric ventilator-associated pneumonia-a South African challenge! S Afr J Crit Care. 2016;32(1):17-20

68. Labhardt ND, Manga E, Ndam M, Balo JR, Bischoff A, Stoll B. Early assessment of the implementation of a national programme for the prevention of mother-to-child transmission of HIV in Cameroon and the effects of staff training: a survey in 70 rural health care facilities. Trop Med Int Health. 2009:14(3):288-93.

69. Levy B, Rao CY, Miller L, Kennedy N, Adams M, Davis R, et al. Ebola infection control in Sierra Leonean health clinics: a large cross-agency cooperative project. Am J Infect Control. 2015;43(7):752-5.

70. Lewin S, Dick J, Zwarenstein M, Lombard CL. Staff training and ambulatory tuberculosis treatment outcomes: a cluster randomized controlled trial in South Africa. Bull World Health Organ. 2005;83(4):250-9.

71. Liautaud A, Adu PA, Yassi A, Zungu M, Spiegel JM, Rawat A, et al. Strengthening human immunodeficiency virus and tuberculosis prevention capacity among south African healthcare workers: a mixed methods study of a collaborative occupational health program. Saf Health Work. 2018;9(2): $172-9$.

72. Liu L, Yin H, Liu D. Zero health worker infection: experiences from the China Ebola treatment unit during the Ebola epidemic in Liberia. Disaster Med Public Health Prep. 2017;11(2):262-6.

73. Mahomed S, Sturm AW, Knight S, Moodley P. An evaluation of infection control in private and public sector intensive care units in South Africa. J Infect Prev. 2018;19(2):87-93.

74. Miceli A, Sebuyira LM, Crozier I, Cooke M, Naikoba S, Omwangangye AP, et al. Advances in clinical education: a model for infectious disease training for mid-level practitioners in Uganda. Int J Infect Dis. 2012;16(10):e708-13.

75. Mbombo N, Bimerew M. Integrating prevention of Mother to Child HIV Transmission competencies into the nursing curriculum: Methodological lessons from a university-based undergraduate programme. Curationis [Internet]. 2012; 35(1):1-10. [cited 2019 Jan 13]. Available from: http://www.scielo.org.za/scielo. php?script=sci_arttext\&pid=\$2223-62792012000100016\&lng=en.

76. Ogoina D, Oyeyemi AS, Ayah O, Onabor AA, Midia A, Olomo WT, et al Preparation and response to the 2014 Ebola virus disease epidemic in Nigeria-the experience of a tertiary hospital in Nigeria. PLoS One. 2016; 11(10):e0165271.

77. Otu A, Ebenso B, Okuzu O, Osifo-Dawodu E. Using a mHealth tutorial application to change knowledge and attitude of frontline health workers to Ebola virus disease in Nigeria: a before-and-after study. Hum Resour Health. 2016;14(5):5.

78. Parker AA, Stephenson R, Riley PL, Ombeki S, Komolleh C, Sibley L, et al. Sustained high levels of stored drinking water treatment and retention of hand-washing knowledge in rural Kenyan households following a clinicbased intervention. Epidemiol Infect. 2006;134(5):1029-36.

79. Richards GA, Brink AJ, Messina AP, Feldman C, Swart K, van den Bergh D, et al. Stepwise introduction of the 'Best care Always' central-line-associated bloodstream infection prevention bundle in a network of South African hospitals. J Hosp Infect. 2017;97(1):86-92.

80. Samuel R, Almedom A, Hagos G, Albin S, Mutungi A. Promotion of handwashing as a measure of quality of care and prevention of hospitalacquired infections in Eritrea: the keren study. Afr Health Sci. 2005:5(1):4-13.

81. Schmitz K, Kempker R, Tenna A, Stenehjem E, Abebe E, Tadessa L, et al. Effectiveness of a multimodal hand hygiene campaign and obstacles to success in Addis Ababa, Ethiopia. Antimicrob Resist Infect Control. 2014;3:8.

82. Shumbusho F, van Griensven J, Lowrance D, Turate I, Weaver MA, Price J, et al. Task shifting for scale-up of HIV care: evaluation of nurse-centered antiretroviral treatment at rural health centers in Rwanda. PLoS Med. 2009; 6(10):e1000163.

83. Speare R, Durrheim D, Ogunbanjo G, Edginton M, Harris B. An effective training strategy for communicable disease control nurses. Afr J Nurs Midwifery. 2003;5(1):50-5.

84. Tillekeratne LG, Linkin DR, Obino M, Omar A, Wanjiku M, Holtzman D, et al. A multifaceted intervention to reduce rates of catheter-associated 
urinary tract infections in a resource-limited setting. Am J Infect Control. 2014;42(1):12-6.

85. Uneke CJ, Ndukwe CD, Nwakpu KO, Nnabu RC, Ugwuoru CD, PrasopaPlaizier N. Stethoscope disinfection campaign in a Nigerian teaching hospital: results of a before-and-after study. J Infect Dev Ctries. 2014; 8(1):86-93.

86. Van Rie A, Sabue M, Jarrett N, Westreich D, Behets F, Kololomani J, et al. Counseling and testing TB patients for HIV: evaluation of three implementation models in Kinshasa, Congo. Int J Tuberc Lung Dis. 2008; 12(3):573-8

87. Wanyu B, Diom E, Mitchell P, Tih PM, Meyer DJ. Birth attendants trained in "prevention of mother-to-child HIV transmission" provide care in rural Cameroon, Africa. J Midwifery Womens Health. 2007;52(4):334-41.

88. Welty TK, Bulterys M, Welty ER, Tih PM, Ndikintum G, Nkuoh G, et al. Integrating prevention of mother-to-child HIV transmission into routine antenatal care: the key to program expansion in Cameroon. J Acquir Immune Defc Syndr. 2005:40(4):486-93.

89. White MC, Millimouno SF. Observational study of three different methods of implementing the WHO surgical safety checklist in Guinea. Glob Anesth Perioper Med. 2016;2(2):158-61.

90. Xi H, Cao J, Liu J, Li Z, Kong $X$, Wang $Y$, et al. Improving health care workers' protection against infection of Ebola hemorrhagic fever through video surveillance. Am J Infect Control. 2016;44(8):922-224.

91. Zaeh S, Kempker R, Stenehjem E, Blumberg HM, Temesgen O, Ofotokun I, et al. Improving tuberculosis screening and isoniazid preventive therapy in an HIV clinic in Addis Ababa, Ethiopia. Int J Tuberc Lung Dis. 2013;17(11): 1396-401.

92. Bedelu M, Ford N, Hilderbrand K, Reuter H. Implementing antiretroviral therapy in rural communities: the Lusikisiki model of decentralized HIV/AIDS care. J Infect Dis. 2007;196(Suppl 3):S464-8.

93. Charalambous S, Grant AD, Day JH, Rothwell E, Chaisson RE, Hayes RJ, et al. Feasibility and acceptability of a specialist clinical service for HIV-infected mineworkers in South Africa. AIDS Care. 2004;16(1):47-56.

94. Harrison A, Karim SA, Flyod K, Ntuli N, Lombard CL, Lurie M, et al. Syndrome packets and health worker training improve sexually transmitted disease case management in rural South Africa: randomized controlled trial. AIDS. 2000;14(17):2769-79.

95. Naidoo S, Taylor M, Esterhuizen TM, Nordstrom DL, Mohamad O, Knight $S E$, et al. Changes in healthcare workers' knowledge about tuberculosis following a tuberculosis training programme. Educ Health. 2011;24(2): 514-20.

96. Morris MB, Chapula BT, Chi BH, Mwango A, Chi HF, Mwanza J, et al. Use of task-shifting to rapidly scale-up HIV treatment services: experiences from Lusaka, Zambia. BMC Health Serv Res. 2009;9:5

97. Perez F, Mukotekwa T, Miller A, Orne-Gliemann J, Glenshaw M, Chitsike I, et al. Implementing a rural programme of prevention of mother-to-child transmission of HIV in Zimbabwe: first 18 months of experience. Trop Med Int Health. 2004;9(7):774-83.

98. Sanne I, Orrell C, Fox MP, Conradie F, Ive P, Zeinecker J, et al. Nurse versus doctor management of HIV-infected patients receiving antiretroviral therapy (CIPRA-SA): a randomised non-inferiority trial. Lancet. 2010;376(9734):33-40.

99. Ssekabira U, Bukirwa H, Hopkins H, Namagembe A, Weaver MR, Sebuyira LM, et al. Improved malaria case management after integrated team-based training of health care workers in Uganda. Am J Trop Med Hyg. 2008;79(6):826-33.

100. Sserwanga A, Harris JC, Kigozi R, Menon M, Bukirwa H, Gasasira A, et al. Improved malaria case management through the implementation of a health facility-based sentinel site surveillance system in Uganda. PLoS One. 2011;6(1):e16316

101. Stringer JS, Zulu I, Levy J, Stringer EM, Mwango A, Chi BH, et al. Rapid scaleup of antiretroviral therapy at primary care sites in Zambia: feasibility and early outcomes. JAMA. 2006;296(7):782-93.

102. Umulisa S, Musabyimana A, Wong R, Adomako E, Budd A, Ntakirutimana T. Improvement of hand hygiene compliance among health professional staff of Neonatology Department in Nyamata Hospital. On Horiz. 2016;24(4):349-56.

103. Driessche V, Sabue M, Dufour W, Behets F, Van Rie A. Training health care workers to promote HIV services for patients with tuberculosis in the Democratic Republic of Congo. Hum Resour Health. 2009;7:23.

104. Workneh G, Scherzer L, Kirk B, Draper HR, Anabwani G, Wanless RS, et al. Evaluation of the effectiveness of an outreach clinical mentoring programme in support of paediatric HIV care scale-up in Botswana. AIDS Care. 2013;25(1):11-9.

105. Olu O, Kargbo B, Kamara S, Wurie AH, Amone J, Ganda L, et al. Epidemiology of Ebola virus disease transmission among health care workers in Sierra Leone, May to December 2014: a retrospective descriptive study. BMC Infect Dis. 2015;15:416.

106. Brownson R, Colditz G, Proctor E. Dissemination and implementation research in health: translating science into practice. 2nd ed. New York: Oxford Univeristy Press; 2018. p. 544.

107. Johnson LG, Armstrong A, Joyce CM, Teitelman AM, Buttenheim AM. Implementation strategies to improve cervical cancer prevention in subSaharan Africa: a systematic review. Implement Sci. 2018;13(1):28.

108. Rowe A, Rowe S, Peters D, Holloway K, Chalker J, Ross-Degnan D. Effectiveness of strategies to improve healthcare provider pracrices in lowincome and middle-income countries: a systematic review. Lancet Glob Health. 2018;6:e1163-e75.

109. Fixen DL, Naoom SF, Blase KA, Friedman RM, Wallace F. Implementation research: a synthesis of the literature. Tampa: Univeristy of South Florida, Network LdIPFMHI--TNIR; 2005. Report No.: 231

110. Wensing M, Bosch M, Grol R. In: Straus S, Tetroe J, Graham I, editors. Knowledge translation in health care: moving from evidence to practice. Oxford: Wiley-Blackwell; 2009. p. 94-113.

111. Powell BJ, Fernandez ME, Williams NJ, Aarons GA, Beidas RS, Lewis CC, et al. Enhancing the impacct of implementation strategies in healthcare: a research agenda. Front Public Health. 2019;7(3). https://doi.org/10.3389/ fpubh.2019.00003.

112. Sackett DL, Rosenberg WM, Muir Gray JA, Haynes RB, Richardson WS. Evidence based medicine: what it is and what it isn't. BMJ. 1996; 312(7023):71-2.

113. Gautier L, Ridde V. Health financing policies in Sub-Saharan Africa: government ownership or donors' influence? A scoping review of policymaking processes. Glob Health Res Policy. 2017;2(23). https://doi.org/ 10.1186/s41256-017-0043-x.

114. Govindaraj R, Herbst C, Clark J. Strengthening post-Ebola health systems: from response to resilience in Guienea, Liberia, and Sierra Leone. Washington, D.C: World Bank Group; 2018.

115. Kaiser Family Foundation. U.S. supported scientists siscover Marburgcarrying bats in West Africa. Washington, DC: KFF; 2019. [cited 2019 Jan 10]. Available from: https://www.kff.org/news-summary/u-s-supported-scientistsdiscover-marburg-carrying-bats-in-west-africa/

\section{Publisher's Note}

Springer Nature remains neutral with regard to jurisdictional claims in published maps and institutional affiliations.

Ready to submit your research? Choose BMC and benefit from:

- fast, convenient online submission

- thorough peer review by experienced researchers in your field

- rapid publication on acceptance

- support for research data, including large and complex data types

- gold Open Access which fosters wider collaboration and increased citations

- maximum visibility for your research: over $100 \mathrm{M}$ website views per year

At $\mathrm{BMC}$, research is always in progress.

Learn more biomedcentral.com/submissions 